\title{
Modification of Apple Pomace by Extrusion Processing: Studies on the Composition, Polymer Structures, and Functional Properties
}

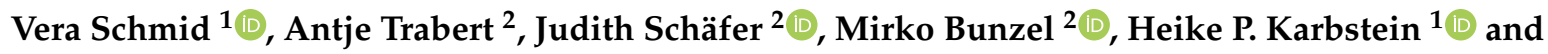 \\ M. Azad Emin 1,* \\ 1 Institute of Process Engineering in Life Sciences, Chair of Food Process Engineering, Karlsruhe Institute of \\ Technology (KIT), 76131 Karlsruhe, Germany; vera.schmid@kit.edu (V.S.); heike.karbstein@kit.edu (H.P.K.) \\ 2 Institute of Applied Biosciences, Department of Food Chemistry and Phytochemistry, Karlsruhe Institute of \\ Technology (KIT), 76131 Karlsruhe, Germany; antje.trabert@kit.edu (A.T.); judith.schaefer@kit.edu (J.S.); \\ mirko.bunzel@kit.edu (M.B.) \\ * Correspondence: azad.emin@kit.edu; Tel.: +49-721-608-48311
}

Received: 1 September 2020; Accepted: 23 September 2020; Published: 1 October 2020

check for updates

\begin{abstract}
By-products of fruit and vegetable processing are an inexpensive and sustainable source of dietary fiber, potentially offering valuable functional properties such as water binding and thickening. Due to these favorable properties, they can be utilized to reformulate widely-consumed foods, e.g., bakery products or beverages. In this study, apple pomace was used as a model system to study whether extrusion technology affects food by-product functionality and thus has the potential to broaden the application of by-products in foods. The effect of the process parameters and the extent of thermo-mechanical treatment on the structural and functional properties of apple pomace were analyzed after extrusion trials using various screw speeds, water contents, and barrel temperatures. Compared to the raw material, apple pomace extruded at $T_{\text {barrel }}=100{ }^{\circ} \mathrm{C}, n=700 \mathrm{~min}^{-1}$ and $m_{\mathrm{H} 2 \mathrm{O}}=17 \%$ showed an increased water solubility up to $33 \%$. The water absorption increased from 5 to $19 \mathrm{~Pa} \cdot \mathrm{s}$ and the paste viscosity from 5 to $339 \mathrm{~Pa} \cdot \mathrm{s}$ by extrusion processing. Analyses of dietary fiber contents and fiber polysaccharide structures revealed that thermo-mechanical stress $\left(n=700 \mathrm{~min}^{-1}\right.$, $m_{\mathrm{H} 2 \mathrm{O}}=22 \%$ ) increased the content of soluble dietary fiber from 12.5 to $16.7 \mathrm{~g} / 100 \mathrm{~g}$ dry matter, and that the harshest conditions even enabled the formation of low-molecular-weight dietary fiber. Arabinans (as neutral rhamnogalacturonan I side chains) appeared to be most sensitive to thermo-mechanical stress, whereas xylans (i.e., a group of minor polysaccharides) were an example of a more stable fiber polysaccharide. Also, the degree of methylation of the pectic polysaccharides was strongly reduced from $50 \%$ to $15 \%$ when thermo-mechanical stress was applied. Imaging and pore size analysis showed that extrusion processing could disrupt the rigid cell wall macromolecular structure.
\end{abstract}

Keywords: upcycling; valorization; by-products; dietary fiber; plant cell wall; non-starch polysaccharides; rheology

\section{Introduction}

Lately, by-products of fruit and vegetable processing have been attracting increasing attention in the fields of food research and industry as affordable, sustainable, and natural sources of both dietary fiber [1,2] and low-molecular-weight bioactive compounds [1,3,4]. Furthermore, they show a wide variety of techno-functional properties, such as water- and oil-absorbing and thickening and gelling properties [5-7]. By partially replacing synthetic food additives, they meet the demand of consumers for more natural and sustainable food products [6,8-10]. The incorporation of fibers can, therefore, impart favorable properties upon foods such as baked goods, dairy products, sausages, and 
beverages. However, the main challenge is that unprocessed by-products commonly have no or low functionality, which limits their application. Since they often unfavorably affect the sensory and/or textural characteristics of food products, they can be added to food systems in limited concentrations only $[5,11-17]$. To increase the amount of dietary fiber without having a negative impact on product's properties, and to utilize the full potential of by-products, significant research is being undertaken on the modification of functional properties, e.g., water absorption and gelling of dietary fiber by various methods such as chemical, enzymatic, thermal, and mechanical treatment $[6,14,18,19]$. Extrusion processing has several advantages as an efficient and continuous process with high flexibility, allowing its application to a wide range of by-products. Modification is often realized through a combination of thermal and mechanical stresses at high concentrations without any need for the use of chemicals. This also eliminates the need for additional separation or drying processes, which reduces the energy needed compared to conventional reactors [20]. The thermal and mechanical stresses applied to raw materials can be widely varied; hence, the molecular structures and functional properties of dietary fiber can be modified, as shown for orange [15,21], citrus [22], and sugar beet pulp [23], as well as onion waste [24].

Plant cell walls from by-products are the major contributors to the dietary fiber content. Depending on several factors such as plant taxonomy, plant organ, plant maturity, etc., the cell wall structure and composition and the structural details of cell wall polysaccharides (and non-carbohydrate polymers such as lignin) vary widely. However, the polymer/polysaccharide compositions and chemical structures are crucial for both the nutritional and functional properties of dietary fiber and by-products. Thermo-mechanical treatment affects the molecular weight and structure of dietary fiber polysaccharides; however, it is not well understood which polysaccharides and which structural elements are the most susceptible to stresses. Being dicotyledonous plants, apples have (primary) cell walls that are dominated by cellulose and pectin, with xyloglucans being the major but quantitatively less important hemicellulose [25].

Apple pomace is currently underutilized as animal feed or as feedstock for the production of bioenergy at producers' expense, and only a small fraction from juice processing is valorized through pectin production $[8,26,27]$. Rarely, it is extruded as a minor ingredient in starch-based matrices to increase the fiber and bioactive content of the extruded products, such as breakfast cereals and snacks [28-31]. The functionalization of mere apple pomace by extrusion processing has been the topic of very few studies [32-34]. It has been shown that the yield of water-soluble polysaccharides can be increased by extrusion processing [32,34]. The shift from insoluble to soluble dietary fiber was explained by the solubilization of mostly non-pectinaceous cell wall polymers; also, partial degradation of the pectinaceous arabinogalactan side-chain was suggested [32]. Furthermore, Hwang et al. showed that hot water-based extraction of pectin from apple pomace can be facilitated by extrusion processing [33].

To the best of our knowledge, no study has been published to date on the changes of both the structure and the functional properties of apple pomace after extrusion processing. Therefore, this study focuses on the application of extrusion processing in order to modify the functional properties of apple pomace with special attention to the analysis of the impact of the process parameters and extrusion conditions on the morphological and structural characteristics of apple pomace.

\section{Materials and Methods}

\subsection{Materials, Chemicals, and Reagents}

Apple pomace (not enzymatically treated, from juice production) with a moisture content of $2.5 \pm 0.3 \%$ (automatic Karl Fischertitration) was kindly supplied by Herbafood Ingredients GmbH (Company of H\&F-Group, Werder (Havel), Germany). According to the supplier, the apple pomace was composed of $60 \%$ dietary fiber, $25 \%$ (digestible) carbohydrates, and $5 \%$ protein. Rapeseed oil was provided by Bernhard Schell GmbH (Lichtenau, Germany). Unless stated otherwise, all chemicals came from Carl Roth (Karlsruhe, Germany), Merck (Darmstadt, Germany), Sigma Aldrich (St. Louis, MO, 
United States) or VWR (Radnor, PA, USA). The heat-stable $\alpha$-amylase Termamyl 120 L (EC 3.2.1.1, from Bacillus licheniformis, $120 \mathrm{KNU} \cdot \mathrm{g}^{-1}$ ), the amyloglucosidase AMG $300 \mathrm{~L}$ (EC3.2.1.3, from Aspergillus niger, $300 \mathrm{AGU} \cdot \mathrm{g}^{-1}$ ) and the protease Alcalase 2.5 L (EC 3.4.21.62, from Bacillus licheniformis, $2.5 \mathrm{AU} \cdot \mathrm{g}^{-1}$ ) were supplied by Novozymes (Bagsværd, Denmark) and were used for the preparative isolation of dietary fiber. Heat-stable $\alpha$-amylase (EC 3.2.11, from Bacillus licheniformis, $3000 \mathrm{U} \cdot \mathrm{mL}^{-1}$ ), amyloglucosidase (EC 3.2.1.3 from Aspergillus niger) and protease (EC 3.4.21.14 from Bacillus licheniformis) (with all three enzymes being used for analytical dietary fiber analysis and the first two being used to determine starch contents), as well as endo-galactanase (EC 3.2.1.89 from Aspergillus niger) and endo-arabinanase (EC 3.2.1.99 from Aspergillus niger) were obtained from Megazymes (Bray, Ireland).

\subsection{Extrusion Trials}

A co-rotating, twin-screw extruder (Coperion ZSK 26Mc, Stuttgart, Germany) with a length-to-diameter ratio (L/D) of 29 and a screw diameter of $25.5 \mathrm{~mm}$ was used to perform the extrusion trials. The screw configuration contained kneading blocks and reverse transport elements (see [35] config.B). The extruder was equipped with a gravimetrically controlled feeder (DDW-DDSR40 from Brabender, Duisburg, Germany) and a piston-membrane pump (model KM 251, Alldos, Pfinztal, Germany). Material and water were fed to the first of the seven sections of the barrel, which could be heated independently. The last three sections were heated to 100 and $120^{\circ} \mathrm{C}$. A circular die of $3 \mathrm{~mm}$ diameter and $10 \mathrm{~mm}$ length was used. All trials were run at a constant total feed rate of $10 \mathrm{~kg} \cdot \mathrm{h}^{-1}$, whereas the water feed was varied among $4 \mathrm{~kg} \cdot \mathrm{h}^{-1}, 2 \mathrm{~kg} \cdot \mathrm{h}^{-1}$ and $1.5 \mathrm{~kg} \cdot \mathrm{h}^{-1}$. The screw speed $n$ was varied among 200, 450, and $700 \mathrm{~min}^{-1}$.

The processing conditions were characterized by the material temperature at the die exit $\left(T_{M}\right)$, and the specific mechanical energy $(S M E)$. $S M E\left(\mathrm{Wh} \cdot \mathrm{kg}^{-1}\right.$ ) was calculated according to Equation (1):

$$
S M E=\frac{\frac{n}{n_{\max }} \times \frac{M_{d}-M_{d, \text { unload }}}{100}}{\dot{m}} \times P_{\max }
$$

where $n$ and $n_{\max }$ are the actual and maximum screw speeds $\left(1800 \mathrm{~min}^{-1}\right), M_{d}$ and $M_{d, \text { unload }}$ are the actual and idle torques (\%), $\dot{m}$ represents the total mass flow $\left(\mathrm{kg} \cdot \mathrm{h}^{-1}\right)$ and $P_{\max }$ the maximum engine power $(40 \mathrm{~kW})$.

Samples were taken upon achieving steady-state conditions and then dried at $4{ }^{\circ} \mathrm{C}$ for $15 \mathrm{~min}$. Extrusion trials were performed in duplicate.

Raw and extruded apple pomace was ground in a coffee mill (M55, Petra Electric, Ense, Germany) and sieved to a particle size of $0.14 \mathrm{~mm}<x<0.28 \mathrm{~mm}$. Afterwards, the samples were dried in a vacuum dryer (Heraeus, Hanau, Germany) at $25^{\circ} \mathrm{C}$ and 8 mbar to constant mass. Most experiments to analyze the techno-functional properties of the raw material and extruded samples were performed using both the non-sieved samples and the fraction with a particle size of $0.14 \mathrm{~mm}<x<0.28 \mathrm{~mm}$, whereas the chemical analyses were only performed using the non-sieved samples.

\subsection{Water Solubility Index and Water Absorption Index}

The water solubility index (WSI) was determined by a modified method according to Anderson [36]. In a $50 \mathrm{~mL}$ centrifuge tube, $0.5 \mathrm{~g}$ of the sample $\left(m_{\text {powder }}\right)$ was dissolved in $19.5 \mathrm{~g}$ demineralized water, mixed for $1 \mathrm{~min}$ with a vortex mixer and afterwards shaken for $24 \mathrm{~h}$ at $200 \mathrm{~min}^{-1}$ in a rotary shaker (Orbital shaker Incubator SI 50, Stuart, Staffordshire, United Kingdom) at room temperature. Samples were centrifuged at $4600 \times g$ for $50 \mathrm{~min}$ at $20^{\circ} \mathrm{C}$. Subsequently, the supernatant was removed and carefully placed into another tube. The precipitate and supernatant were dried in a drying oven at $80^{\circ} \mathrm{C}$ for $72 \mathrm{~h}$ and weighed. WSI were calculated using Equation (2). On the assumption that the rigid cell wall would be loosened by extrusion processing, centrifugation would squeeze out loosely bound water. Thus, the water absorption index (WAI) was determined similarly to the common method 
(Anderson [36]) described above, but without the centrifugation step. Samples rested for $3 \mathrm{~h}$ to separate by sedimentation. WAI was calculated according to Equation (3).

$$
\begin{gathered}
\text { WSI }=\frac{m_{\text {supernatant, dried }}}{m_{\text {powder }}} \\
W A I=\frac{m_{\text {preciptate, wet }}-m_{\text {preciptated, dried }}}{m_{\text {preciptated, dried }}}
\end{gathered}
$$

WSI and WAI of selected samples were measured for extrusion trials 1 and 2. No significant difference were observed. Therefore, the analyses of WSI and WAI were performed only in triplicate using one extrudate.

\subsection{Oil Binding Capacity}

The oil binding capacity (OBC) was determined by a modified method introduced by Caprez et al. [37]. Sample ( $0.5 \mathrm{~g}$; prepared according to 2.2) was added to $10 \mathrm{~g}$ of rapeseed oil, vortexed for $1 \mathrm{~min}$ and shaken for $24 \mathrm{~h}$ (200 $\mathrm{min}^{-1}$, Universal Shaker SM30C, Edmund Bühler, Bodelshausen, Germany). Samples were centrifuged at $4250 \times g$ for $50 \mathrm{~min}$ at $25^{\circ} \mathrm{C}$. Subsequently, the supernatant was carefully transferred to another tube and weighed. The oil binding capacity was defined as the amount of oil that was absorbed by the sample, and was calculated by Equation (4).

$$
\mathrm{OBC}=\frac{m_{\text {oil }, \text { added }}-m_{\text {oil }} \text { removed }}{m_{\text {powder }}}
$$

\subsection{Rheological Properties}

To characterize the rheological properties, $1 \mathrm{~g}$ of sample prepared according to the description in Section 2.2 was added to $10 \mathrm{~g}$ of demineralized water. The sample was stirred for $10 \mathrm{~min}$ and $200 \mathrm{~min}^{-1}$ (magnetic mixer) and stored at room temperature for $50 \mathrm{~min}$, sealed with parafilm. Samples were measured in an Anton Paar MC 301 rheometer (Graz, Austria) using a parallel plate with a diameter of $50 \mathrm{~mm}$ and a gap of $2 \mathrm{~mm}$. The measurement routine started with $90 \mathrm{~s}$ of rest. Afterwards, the sample was subjected to oscillatory shear measurements with an amplitude of $0.1 \%$ and a frequency of $1 \mathrm{~Hz}$ at $25^{\circ} \mathrm{C}$, which is in the linear viscoelastic region of the sample. To determine the complex viscosity $\eta^{*}$, a mean value of nine measurement points of each measurement was considered. The measurements were performed in triplicate using one extrudate.

\subsection{Chemical Analysis}

All data are presented as mean \pm standard deviation ( $n=3$ using one extrudate). All data from structural analyses of isolated dietary fiber (molecular weight distribution, monosaccharide composition and linkage, arabinan and galactan oligosaccharides) are given as mean \pm range/2 $(n=2)$.

Free mono- and disaccharides. Water $(10 \mathrm{~mL})$ was added to $200 \mathrm{mg}$ of sample in a $15 \mathrm{~mL}$ tube. The suspension was vortexed and treated for $10 \mathrm{~min}$ in an ultrasonic bath (temperature $<30{ }^{\circ} \mathrm{C}$ ). After $5 \mathrm{~min}$, the solution was centrifuged for $10 \mathrm{~min}$, and the supernatant was collected in a $50 \mathrm{~mL}$ volumetric flask. The extraction steps were repeated four times. The combined extracts were adjusted to $50 \mathrm{~mL}$, and a $2 \mathrm{~mL}$ aliquot was filtered through a PTFE membrane filter $(45 \mu \mathrm{m})$. A $200 \mu \mathrm{L}$ aliquot was mixed with $800 \mu \mathrm{L}$ of ethanol; precipitation was completed within $10 \mathrm{~min}$. After centrifugation, the supernatant was transferred and evaporated. The residue was redissolved in $200 \mu \mathrm{L}$ of water, $20 \mu \mathrm{L}$ of $\mathrm{D}$-fucose $(200 \mu \mathrm{M})$ was added as internal standard, and the solution was analyzed using HPAEC-PAD [38].

Starch content. The starch content was determined after enzymatic digestion by analysis of liberated glucose using HPAEC-PAD. The sample $(1 \mathrm{~g})$ was suspended in $50 \mathrm{~mL}$ of $0.08 \mathrm{M}$ phosphate buffer ( $\mathrm{pH}$ 6.0), and the suspension was heated for $15 \mathrm{~min}$ at $60^{\circ} \mathrm{C}$. Thermostable $\alpha$-amylase $(1 \mathrm{~mL})$ was 
added, and the suspension was heated for $15 \mathrm{~min}$ at $92^{\circ} \mathrm{C}$. After cooling to room temperature, the $\mathrm{pH}$ was adjusted to $4.5,100 \mu \mathrm{L}$ of amyloglucosidase solution $\left(10 \mathrm{mg} \cdot 100 \mu \mathrm{L}^{-1}\right)$ was added, and the suspension was heated for $15 \mathrm{~min}$ at $60^{\circ} \mathrm{C}$, followed by adjusting the volume to $100 \mathrm{~mL}$. To an aliquot of $4 \mathrm{~mL}, 1 \mathrm{~mL}$ of Carrez I (150 g. $\left.\mathrm{L}^{-1} \mathrm{~K}_{4}\left[\mathrm{Fe}(\mathrm{CN})_{6}\right] \cdot 3 \mathrm{H}_{2} \mathrm{O}\right)$ and $1 \mathrm{~mL}$ of Carrez II $\left(300 \mathrm{~g} \cdot \mathrm{L}^{-1} \mathrm{ZnSO}_{4} \cdot 7 \mathrm{H}_{2} \mathrm{O}\right)$ solutions were added, and the $\mathrm{pH}$ was adjusted to 7.5-8.0. Following centrifugation and volume adjustment, the solution was diluted for analysis by HPAEC-PAD and $20 \mu \mathrm{L}$ of the internal standard D-Fucose $(200 \mu \mathrm{M})$ was added. Monosaccharide (glucose) analysis was performed as previously described by Wefers, Gmeiner et al. [38]. The starch content was calculated as the sum of anhydroglucose.

Dietary fiber analysis. To determine the insoluble, soluble and low-molecular-weight soluble dietary fiber contents excluding resistant starch, a combination of the procedures AOAC 985.29 [39] and AOAC 2009.01 [40] was performed. In brief, the ground material (1 g; particle size $<0.5 \mathrm{~mm}$ ) was first digested with a thermostable amylase $\left(\mathrm{pH} 6.0,20 \mathrm{~min}, 92^{\circ} \mathrm{C}\right)$, then with a protease $(\mathrm{pH} 7.5$, $30 \mathrm{~min}, 60^{\circ} \mathrm{C}$ ) and finally with an amyloglucosidase ( $\left.\mathrm{pH} 4.5,30 \mathrm{~min}, 60^{\circ} \mathrm{C}\right)$. The warm solution was filtered through Celite crucibles. Residues were washed with water, ethanol and acetone. The residue remaining in the crucible corresponded to the uncorrected insoluble dietary fiber and could be weighed after drying overnight at $105^{\circ} \mathrm{C}$. The filtrate and water washing were combined, and soluble dietary fiber was precipitated by adding four times the volume of ethanol. The residue was separated by filtration through crucibles and washed with ethanol and acetone. This residue, after drying at $105^{\circ} \mathrm{C}$, corresponded to the uncorrected soluble dietary fiber. Both insoluble and soluble dietary fiber contents were corrected for ash (gravimetrically after combustion at $520^{\circ} \mathrm{C}$ ) and residual protein contents (ammonia detection using an ammonia electrode after Kjeldahl digestion; $\mathrm{N} \times 6.25$ [41]). The filtrate obtained from the isolation of soluble dietary fiber was evaporated to almost dryness by rotary evaporation, redissolved in water, adjusted to a defined volume and desalted on a column filled with Amberlite FPA53/Ambersep 200 (Megazyme, Bray, Ireland). Elution was carried out with water. The eluate was evaporated and redissolved in a defined volume of water. Low-molecular-weight dietary fiber oligosaccharides were separated from mono- and disaccharides and quantitated by HPLC (Hitachi, Merck, Darmstadt, Germany) with refractive index (RI) detection (Knauer, Berlin, Germany) using a TSKgel G2500PWxl column (300 $\mathrm{mm} \times 7.8 \mathrm{~mm}, 7 \mu \mathrm{m}$ particle size, Tosoh, Tokyo, Japan). The elution was performed with water at $60{ }^{\circ} \mathrm{C}$ using a flow rate of $0.4 \mathrm{~mL} \cdot \mathrm{min}^{-1}$. The boundary (elution time) between di- and oligosaccharides was determined by analysis of maltose and maltotriose. Quantification was performed using glycerol, which was added before the first filtration step as an internal standard; D-glucose was used to determine the response factor.

Preparative dietary fiber isolation. The isolation of soluble and insoluble dietary fiber was carried out using the principles of the AOAC 985.29 method (enzymatic treatment using thermostable $\alpha$-amylase, protease, and amyloglucosidase); however, it was modified to allow for a separation of soluble and insoluble dietary fiber on a preparative scale, as described by Bunzel et al. [42]. The structural analyses described below were performed using these dietary fiber preparations.

Molecular weight distribution. To determine the molecular weight distribution of soluble fiber polysaccharides, soluble dietary fiber samples were dissolved in $50 \mathrm{mM}$ sodium nitrate solution $\left(2 \mathrm{mg} \cdot \mathrm{mL}^{-1}\right)$ within $24 \mathrm{~h}$ at $40{ }^{\circ} \mathrm{C}$. These were analyzed by HPLC-RI (Hiatchi, Merck, Darmstadt, Germany) using a TSK-gel G4000PWxl column ( $300 \mathrm{~mm} \times 7.8 \mathrm{~mm}$, particle size $10 \mu \mathrm{M}$, Tosoh). Sodium nitrate $(50 \mathrm{mM})$ was used as eluent, and a flow rate of $0.5 \mathrm{~mL} \cdot \mathrm{min}^{-1}$ and a temperature of $40{ }^{\circ} \mathrm{C}$ were maintained. Calibration was performed using dextrans as standard polysaccharides.

Polysaccharide composition. The monosaccharide composition of insoluble, soluble (and low-molecular-weight soluble; obtained from the analytical dietary fiber approach) dietary fiber carbohydrates was determined as described by Wefers, Gmeiner et al. [38]. In brief, insoluble dietary fiber polysaccharides were hydrolyzed by using sulfuric acid hydrolysis, whereas soluble dietary fiber polysaccharides were hydrolyzed by using methanolysis followed by trifluoroacetic acid (TFA) hydrolysis. Liberated monosaccharides were analyzed by HPAEC-PAD. This procedure was modified to analyze the monosaccharide composition of the low-molecular-weight soluble dietary fiber 
carbohydrates. These were preparatively purified by HPLC (Hiatchi, Merck, Darmstadt, Germany) with RI detection (Knauer, Berlin, Germany) using a TSKgel G2500PWxl column. The elution was performed with water at $60{ }^{\circ} \mathrm{C}$ and a flow rate of $0.4 \mathrm{~mL} \cdot \mathrm{min}^{-1}$. The elution window (16 to $38.6 \mathrm{~min}$ ) of the oligosaccharide fraction was adopted from the analysis of low-molecular-weight (ethanol) soluble dietary fiber described above. Collected solutions were evaporated and re-dissolved in a defined volume of water. An aliquot of this solution $(20 \mu \mathrm{L})$ was evaporated and treated with $500 \mu \mathrm{L}$ of a $2 \mathrm{M}$ TFA solution for $1 \mathrm{~h}$ at $121^{\circ} \mathrm{C}$, followed by evaporation. Twice, ethanol was added and evaporated. The residue was dissolved in $180 \mu \mathrm{L}$ of water, $20 \mu \mathrm{L}$ of $1 \mathrm{mM}$ D-mannitol was added and the solution was analyzed using HPAEC-PAD.

Polysaccharide linkage analysis. The analysis of interunit linkages of insoluble and soluble fiber polysaccharides was carried out as described by Gniechwitz et al. [43]. In brief: methylation using methyl iodide in DMSO/NaOH; extraction into dichloromethane; hydrolysis using $2 \mathrm{M}$ TFA at $121^{\circ} \mathrm{C}$ for 90 min; reduction using $\mathrm{NaBD}_{4}$; acetylation in acetic anhydride using 1-methylimidazole as catalyst; identification of partially methylated alditol acetates by GC-MS; and semiquantitation by GC-FID using a molar response factor as described by Sweet et al. [44].

Arabinan and galactan screening. Arabinans and galactans as neutral pectic (rhamnogalacturonan I) side chains were analyzed by using a profiling approach established by Wefers, Bunzel et al. [45]. In brief, after enzymatic digestion with endo-arabinanase and endo-galactanase, the arabinan and galactan oligosaccharides were determined semiquantitatively using HPAEC-PAD.

Degree of (pectin) esterification. To measure the degree of esterification, polymer-bound galacturonic acid was analyzed photometrically using the method described by Blumenkrantz et al. [46]. The methanol content was measured by NMR after alkaline hydrolysis. Sodium hydroxide solution in $\mathrm{D}_{2} \mathrm{O}(2 \mathrm{M}, 1 \mathrm{~mL})$ and $0.1 \mathrm{~mL}$ of a $0.2 \mathrm{mg} \cdot \mathrm{mL}^{-1} 3$-(trimethylsilyl)propionic-2,2,3,3- $d_{4}$ acid sodium salt solution in $\mathrm{D}_{2} \mathrm{O}$ (as an internal standard) were added to $15 \mathrm{mg}$ of sample material. The hydrolysis was carried out for $2 \mathrm{~h}$ in an ultrasonic bath. After centrifugation and membrane filtration (PTFE; $0.45 \mu \mathrm{m}$ ), the solution was analyzed using ${ }^{1} \mathrm{H}-\mathrm{NMR}$ spectroscopy (Avance $500 \mathrm{MHz}$ instrument with a Prodigy cryoprobe; Bruker, Rheinstetten, Germany). A standard Bruker ${ }^{1} \mathrm{H}-\mathrm{NMR}$ pulse program (zg30) was used, and the following parameters were applied: 65,536 data points, acquisition time $3.28 \mathrm{~s}$ and relaxation delay (D1) $35 \mathrm{~s}$. Processing was done using zero filling, a by factor of two and application of a Lorentz function (EM, $0.3 \mathrm{~Hz}$ ).

\subsection{Simons' Stain}

Simons' stain method was performed according to the Modified Simons' stain technique described by Chandra et al. [47]. Instead of Direct Blue 1 and Direct Orange 15, Direct Red 28 (DR 28, Congo Red, CAS: 573-58-0, Carl Roth GmbH \& Co. KG, Karlsruhe, Germany) and Direct Yellow 4 (DY 4, CAS: 3051-11-4, Sigma-Aldrich Chemie GmbH/Merck KGaA, Munich, Germany) were used [48,49]; because in their study, DR 28 and DY 4 provided the most accessible surface values. Dye concentration was $1 \%$ $(w / w)$. The measurements were performed in triplicate using one extrudate.

\section{Results and Discussion}

\subsection{Influence of Extrusion Parameters on the Extent of Thermo-Mechanical Treatment}

To better understand and control the impact of extrusion parameters (e.g., screw speed, barrel temperature and water content) on the modification of the functional properties of apple pomace, their influence on the resulting processing conditions, namely the thermal and mechanical stress profiles, were analyzed. For this purpose, the specific mechanical energy (SME) and material temperature $\left(T_{M}\right)$ were used as indicators (Figures 1 and 2). 

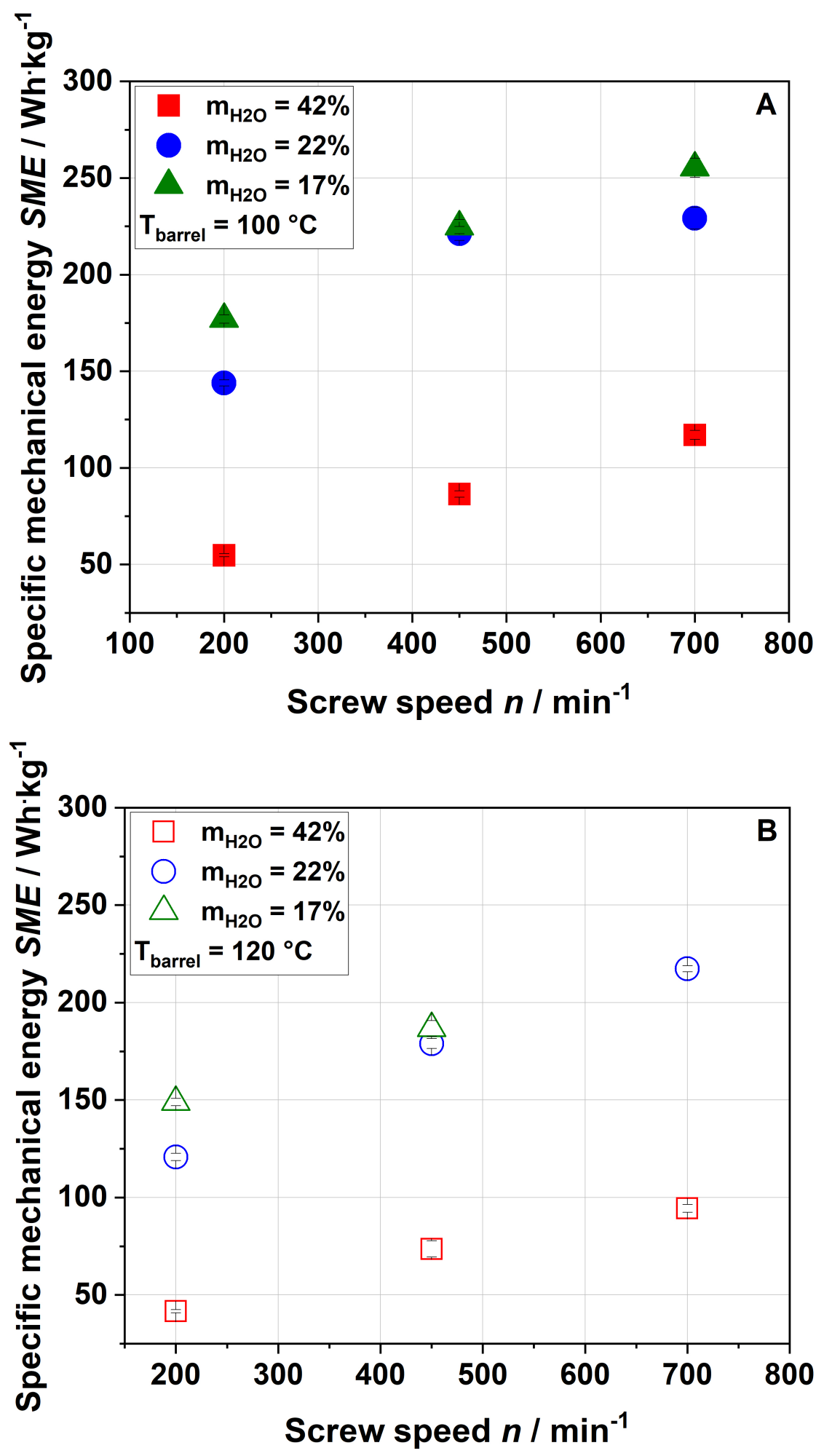

Figure 1. Effect of screw speed and water content on the specific mechanical energy (SME) at (A) $100{ }^{\circ} \mathrm{C}$ barrel temperature and (B) $120^{\circ} \mathrm{C}$ barrel temperature. 

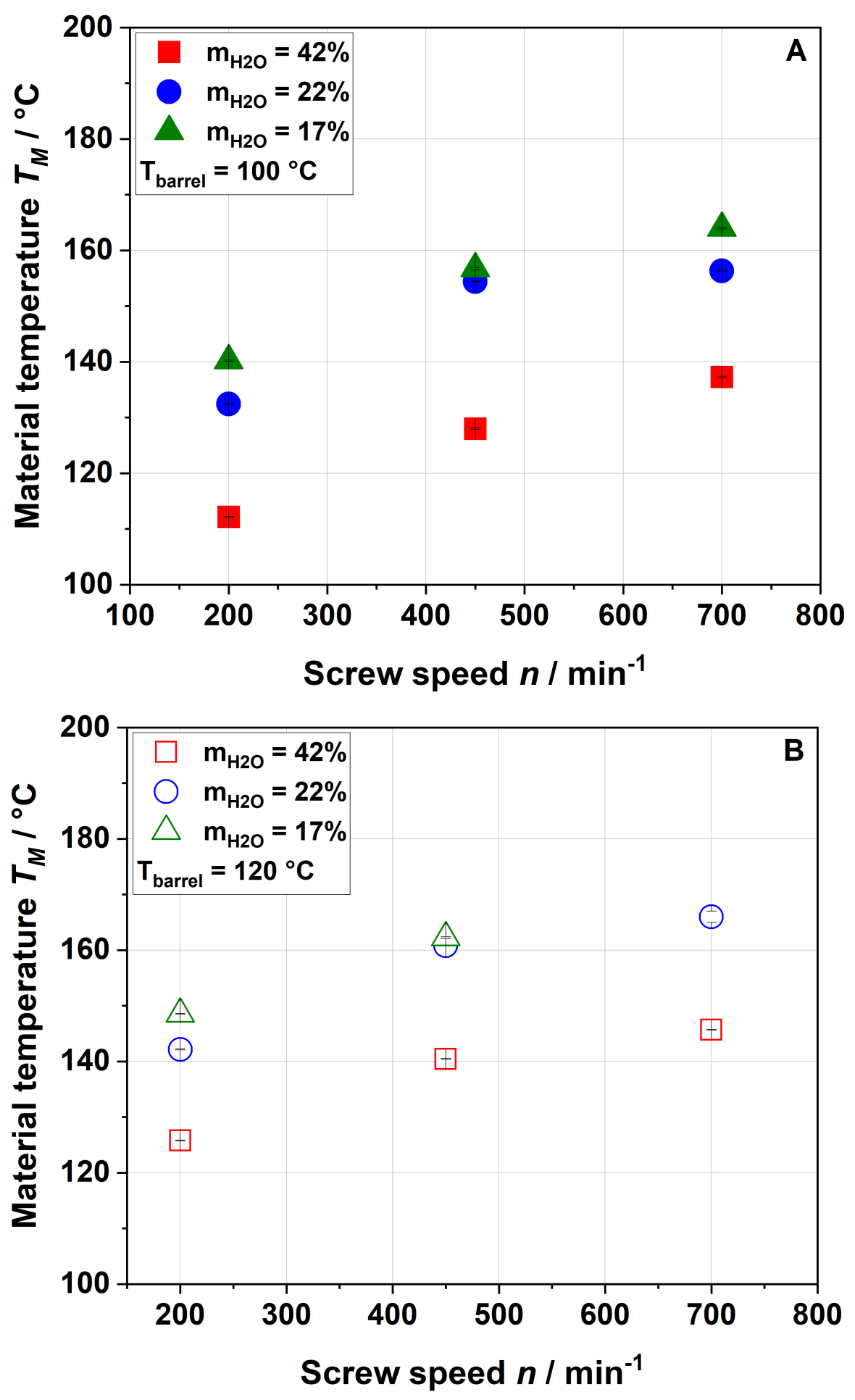

Figure 2. Effect of screw speed and water content on the material temperature $\left(T_{M}\right)$ measured at the die entrance at (A) $100{ }^{\circ} \mathrm{C}$ barrel temperature and (B) $120^{\circ} \mathrm{C}$ barrel temperature.

As expected, an increase in screw speed led to an increase in SME. Reducing the water content from $42 \%$ to $22 \%$ resulted in a strong increase in SME due to the higher viscosity of the melt, whereas a further decrease in water content, i.e., to $17 \%$, led to a slight increase only or even to no further increase in SME. A barrel temperature of $120^{\circ} \mathrm{C}$ (Figure 1B) resulted in a lower SME at the same screw speed and water content compared to a barrel temperature of $100^{\circ} \mathrm{C}$ (Figure 1A). This was potentially due to the temperature dependence of the matrix viscosity (lower viscosity at higher temperature) 
resulting in lower mechanical shear stresses [50]. No samples were taken at a water content of $17 \%$, barrel temperature of $120^{\circ} \mathrm{C}$ and screw speed of $700 \mathrm{~min}^{-1}$ due to the instability of the process.

Figure 2 shows that the material temperature was always higher than the barrel temperature, indicating that viscous dissipation (resulting from the mechanical energy) plays an important role in the extrusion process of apple pomace.

The rising screw speed further increased the material temperature. Also, decreasing the water content from $42 \%$ to $22 \%$ resulted in a significantly higher material temperature, whereas a further decrease to $17 \%$ had only a minor impact (cf. the SME data shown in Figure 1). Again, this suggests that heating of the material was mainly driven by the viscous dissipation coupled to mechanical stress. As expected, an increase in the barrel temperature from $100{ }^{\circ} \mathrm{C}$ (Figure 2A) to $120^{\circ} \mathrm{C}$ (Figure 2B) resulted in a higher material temperature.

\subsection{Influence of Extrusion Conditions on Functional Properties}

Fibers can impart favorable functional properties upon foods. Most food matrices are water-based, and therefore, the functional properties regarding the interaction of fibers with water are crucial. The water solubility index describes the amount of fiber which solubilizes in water. The amount of water that can be absorbed by a sample is defined as the water absorption index. These indices are essential to adjust textural properties like viscosity in yogurts, to avoid syneresis in dairy products or to maintain the moisture in, e.g., bread or sausages. Water absorption also plays a major role in the digestion of foods. Some foods are characterized by a high amount of fat-like creams or emulsions. Therefore, also the oil-binding capacity was determined.

The results in Section 3.2.1, Section 3.2.2, Section 3.2.3, Section 3.2.4 describe the data obtained from using the sieved fraction of the raw material and the extruded samples (particle size of $0.14 \mathrm{~mm}<$ $x<0.28 \mathrm{~mm}$ ).

\subsubsection{Water Solubility}

Figure 3 shows the influence of screw speed on the water solubility index (WSI) of raw and extruded apple pomace.

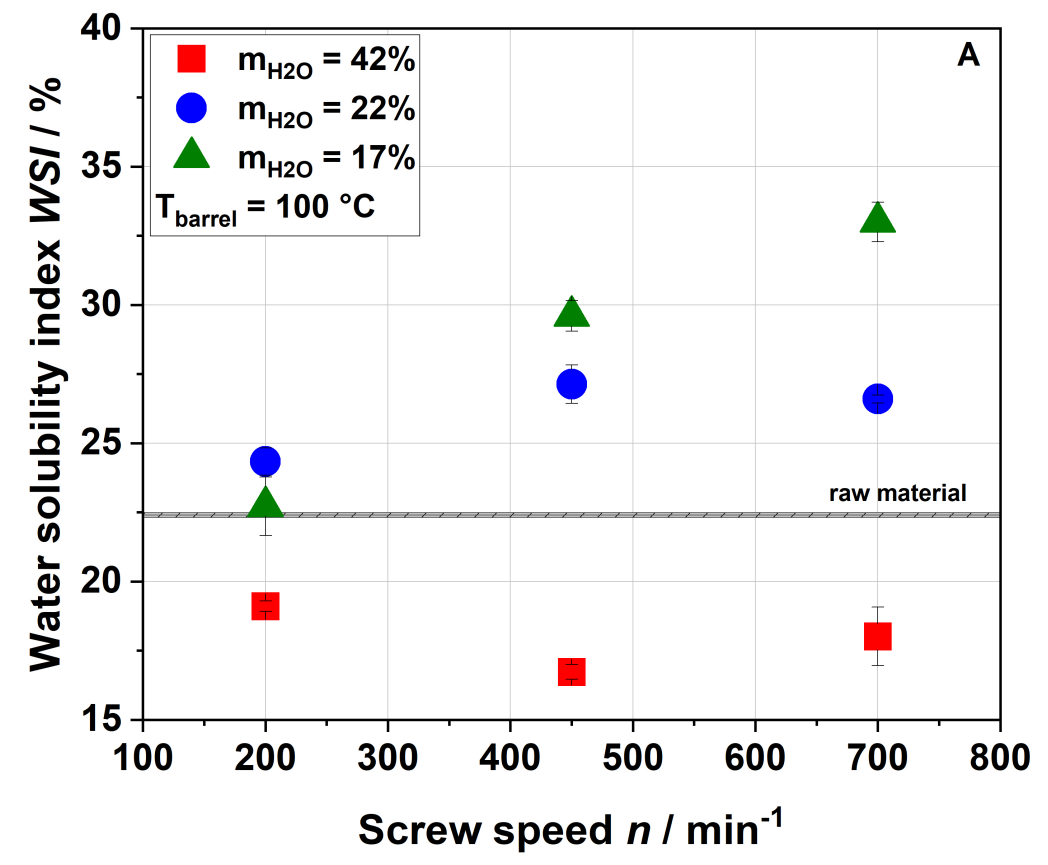

Figure 3. Cont. 


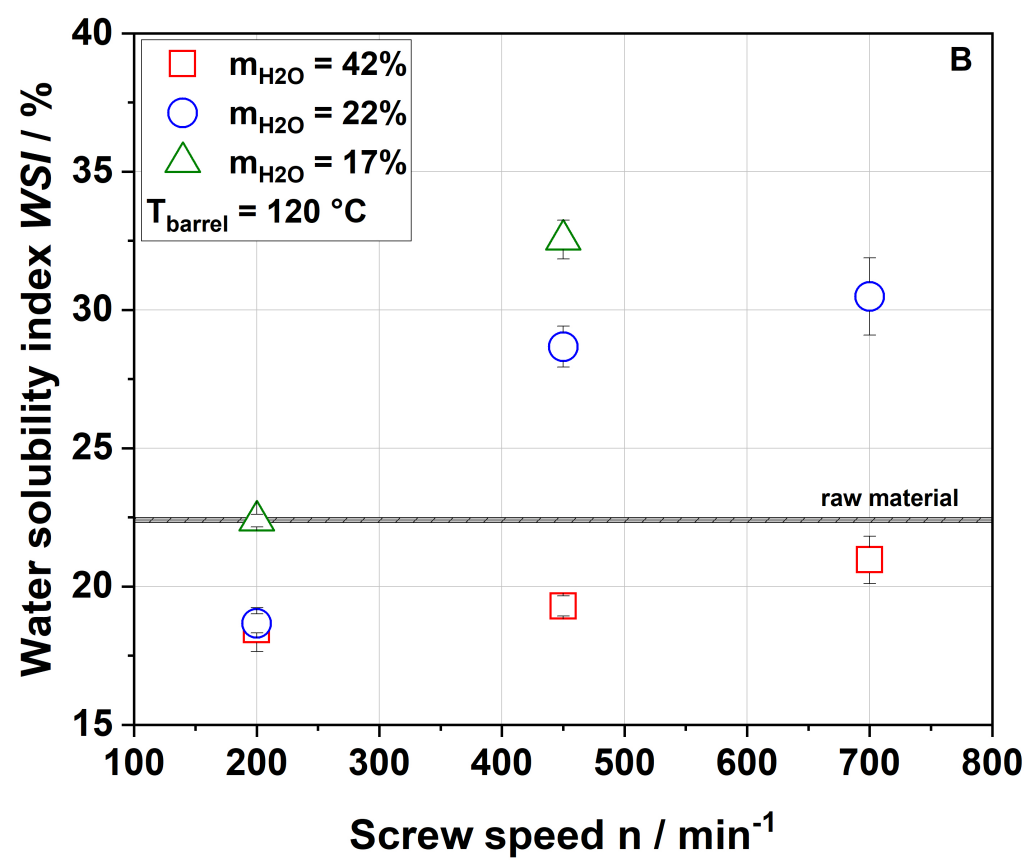

Figure 3. Effect of screw speed and water content on the water solubility index (WSI) at (A) $100{ }^{\circ} \mathrm{C}$ barrel temperature and (B) $120^{\circ} \mathrm{C}$ barrel temperature. Values of the raw material are marked as a black line, whereas values of extruded samples are given as dots.

For a water content of $42 \%$, the WSI of the extruded samples was lower than that of the raw material for all screw speeds and barrel temperatures investigated. This can be explained either by agglomeration due to extrusion processing or by structural changes (see Section 3.3). For water contents of $17 \%$ and $22 \%$ and a barrel temperature of $100{ }^{\circ} \mathrm{C}$, the WSI of raw and extruded samples were roughly comparable at $200 \mathrm{~min}^{-1}$, whereas an increase in screw speed resulted in a higher water solubility of the extruded samples. The highest WSI was achieved at the lowest water content and highest screw speed, at which both $\mathrm{SME}$ and $\mathrm{T}_{\mathrm{M}}$ reached their maxima (see Figure 1).

A similar trend was also observed by Hwang et al. [32] and Liu et al. [34], although they reported significantly higher values of WSI for both raw material (22.4-35\%) and extruded apple pomace $(49.6-57.8 \%)$. These deviations may have been due to differences in the raw material (e.g., enzymatically vs. not enzymatically treated pomace) and the processing parameters (e.g., different extruder and screw configurations) used. The above authors related the increase in WSI to the solubilization of the rigid cell wall structure, which was caused by increasing mechanical stresses [32]. However, a parallel increase in material temperature was not discussed. Chang et al. showed that thermal treatment only (achieved by autoclaving) also resulted in higher amounts of soluble fibers [51], which indicated that thermal stresses could be equally important for an increased solubility of apple pomace at higher screw speeds.

The WSI data of the samples extruded at a higher barrel temperature (Figure 3B) demonstrate higher water solubilities at screw speeds of 450 and $700 \mathrm{~min}^{-1}$. This was potentially related to the higher thermal treatment. Analysis of the processing conditions (Figures 1 and 2) showed that increasing the barrel temperature resulted in higher material temperatures but lower SME, again suggesting that thermal stresses are important for the modification of apple pomace.

Apple pomace is mainly composed of cellulose, hemicelluloses and pectins, with cellulose being insoluble. Unlike cellulose, hemicelluloses and pectins are partially water soluble. An increase in water solubility was often attributed to increasing amounts of water-soluble pectic and hemicellulosic polymers [32], which was also shown for lemon fibers [52,53]. Previous studies also showed that extrusion may result in lower portions of arabinose and galactose in the water-insoluble residues indicating a solubilization of pectic substances during extrusion processing [23,32]. 


\subsubsection{Water Absorption}

Samples extruded at water contents of $17 \%$ and $22 \%$ showed a higher water absorption index (WAI) than the raw material, whereas samples that were processed at the highest water content of $42 \%$ showed no significant change in WAI regardless of the screw speed applied (Figure 4A,B).
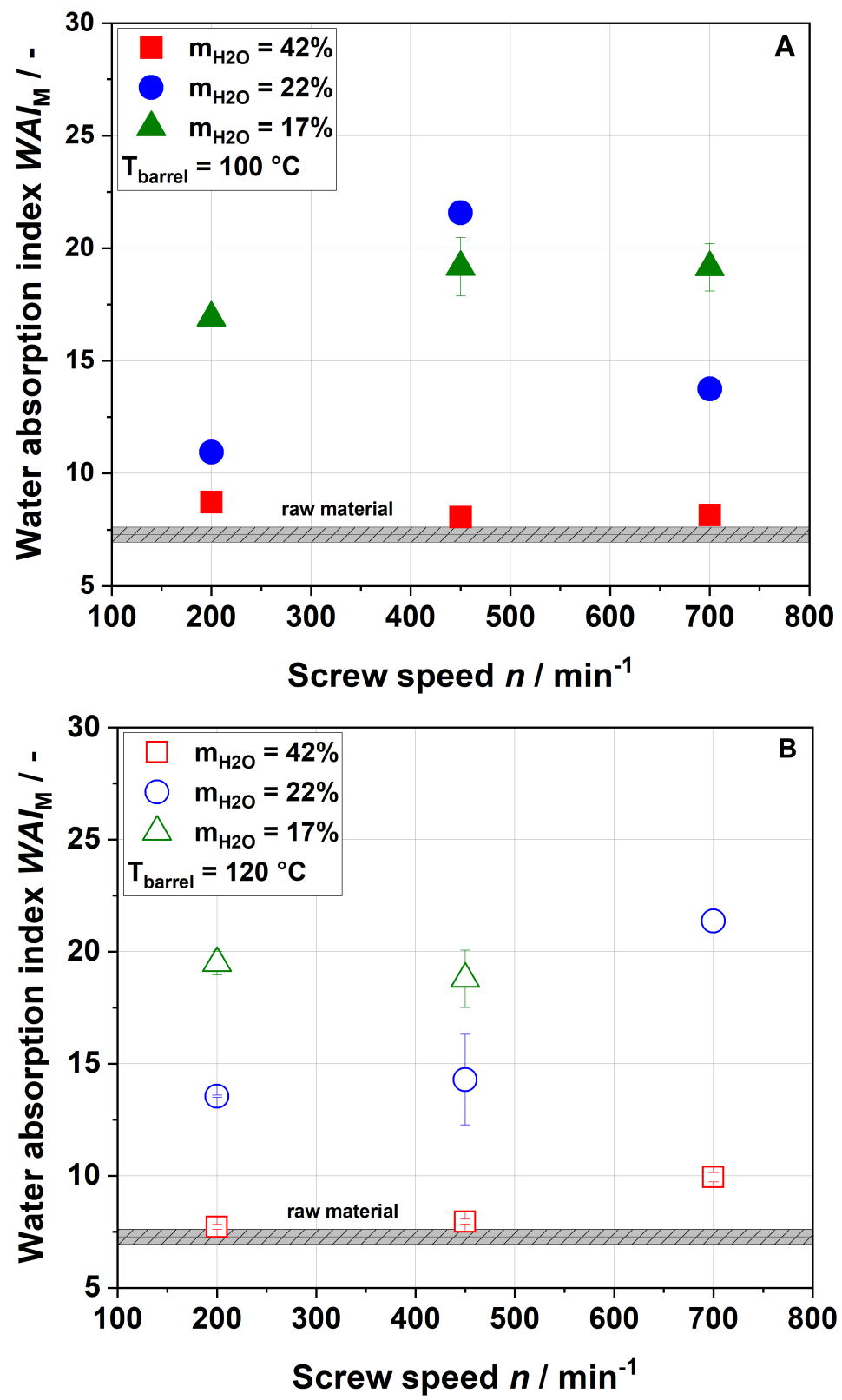

Figure 4. Effect of screw speed and water content on the modified water absorption index (WAI) at (A) $100{ }^{\circ} \mathrm{C}$ barrel temperature and (B) $120^{\circ} \mathrm{C}$ barrel temperature.

At a water content of $17 \%$ and a barrel temperature of $100{ }^{\circ} \mathrm{C}$, an increase in screw speed from 200 to $450 \mathrm{~min}^{-1}$ led to higher WAI. At a water content of $22 \%$, the maximum WAI was observed for a screw speed of $450 \mathrm{~min}^{-1}$. At a higher barrel temperature of $120^{\circ} \mathrm{C}$, WAI differed depending on the water contents during extrusion $(17 \%$ or $22 \%$ ) at all screw speeds, with higher WAI at a water content of $22 \%$.

In the literature, for other by-products, mostly decreases in WAI with increasing thermo-mechanical treatment have been reported $[24,54]$. This can be explained by the centrifugation step used in these studies. In order to identify the exact amount of water that can be taken up by a sample, no 
centrifugation step was performed in this study. The increase in WAI was most likely due to changes in the cell wall structure, which might be opened up during extrusion processing. Higher porosity results in absorbing more water during rehydration [55], as discussed in more detail in Section 3.4.

\subsubsection{Oil-Binding Capacity}

The oil-binding capacity $(\mathrm{OBC})$ of raw and extruded apple pomace is displayed in Figure 5 as a function of the screw speed, water content and barrel temperature.

Figure 5 shows that extrusion treatment did not change the OBC of the samples. A low OBC value (1.23), which did not significantly change after extrusion treatment, is also reported for orange pomace [21]. Although these results suggest that extrusion processing did not result in major changes of the lipophilic functional groups of cell wall molecules, the degree of pectin methylation and acetylation decreased with increased thermo-mechanical stress, as detailed in Section 3.3.
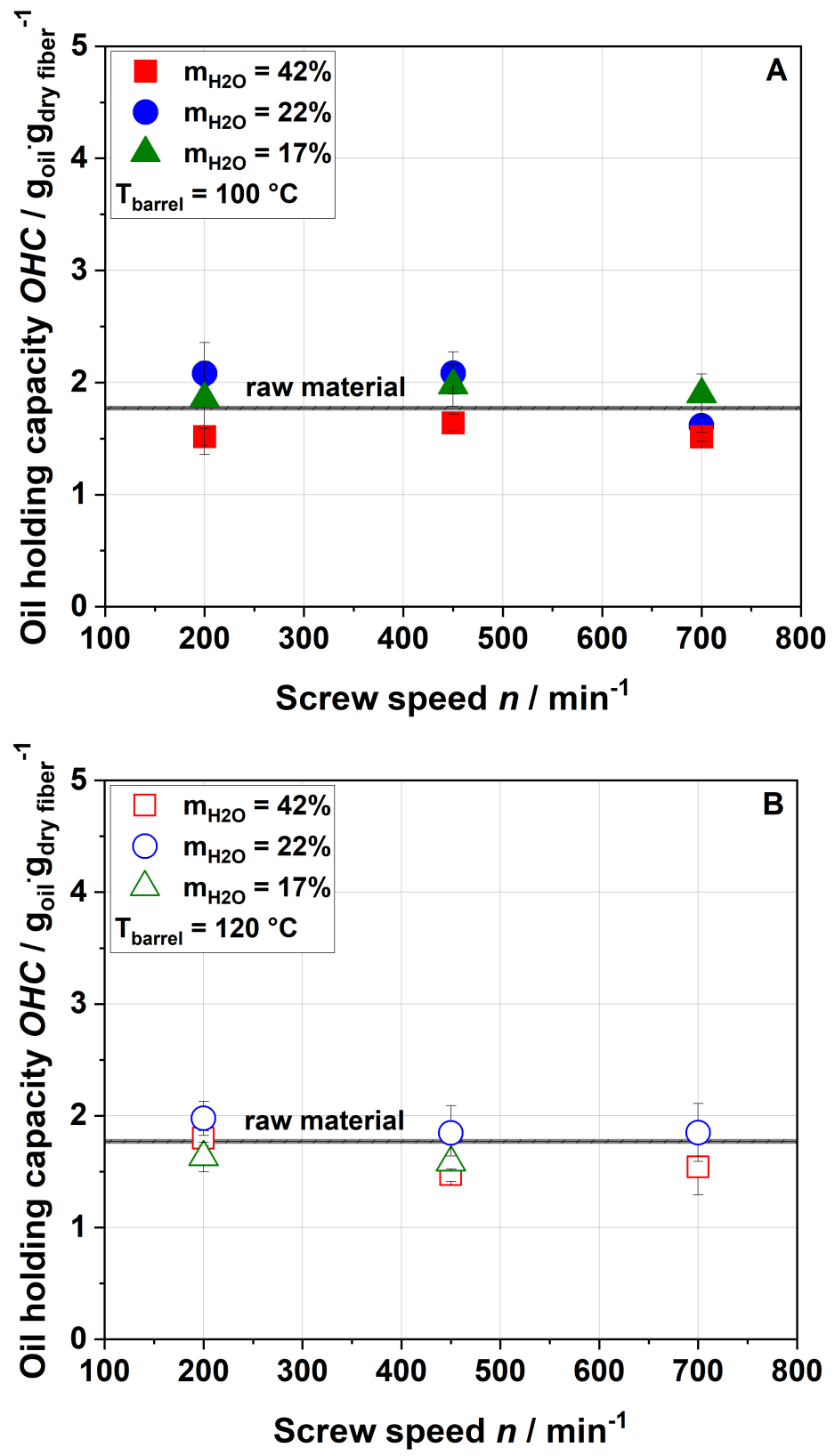

Figure 5. Effect of screw speed and water content on the oil-binding capacity (OBC) at (A) $100{ }^{\circ} \mathrm{C}$ barrel temperature and (B) $120^{\circ} \mathrm{C}$ barrel temperature. 


\subsubsection{Gelation Properties}

The effect of extrusion processing on the paste viscosity of water dispersions of apple pomace is depicted in Figure 6.
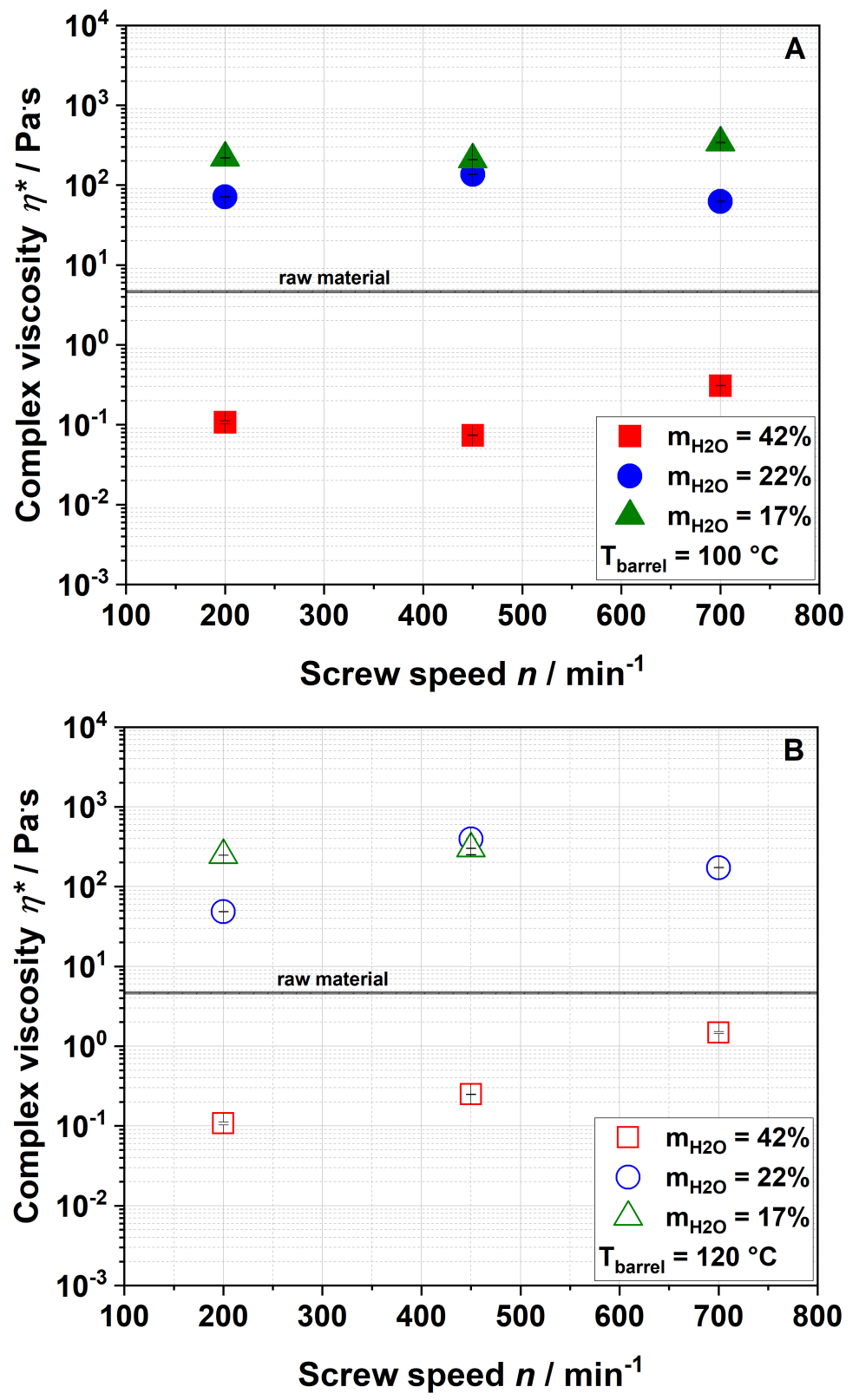

Figure 6. Effect of screw speed and water content on complex viscosity $\eta^{*}$ at (A) $100{ }^{\circ} \mathrm{C}$ barrel temperature and (B) $120^{\circ} \mathrm{C}$ barrel temperature.

A water dispersion of the raw material had a complex viscosity of $4.6 \mathrm{~Pa} \cdot \mathrm{s}$ (Figure 6). Samples extruded at a water content of $42 \%$ formed even weaker pastes than raw apple pomace which, however, increased with screw speed at an elevated barrel temperature of $120^{\circ} \mathrm{C}$ (Figure 6B). Samples that were extruded at lower water contents showed higher complex viscosities than the raw material. By decreasing the water content to $22 \%$ during extrusion, the complex viscosity of the samples extruded at a screw speed of $200 \mathrm{~min}^{-1}$ (barrel temperature: $100{ }^{\circ} \mathrm{C}$ ) increased to $71.1 \mathrm{~Pa} \cdot \mathrm{s}$. Under these conditions, a further reduction of the water content to $17 \%$ led to a complex viscosity of $218.6 \mathrm{~Pa} \cdot \mathrm{s}$. Figure 7 shows pictures of the water dispersions of apple pomace extruded at water contents of either $42 \%$ or $17 \%$, demonstrating different gelling behaviors. 
Apparently, complex viscosity is not linearly dependent on the screw speed. Nevertheless, the results show that complex viscosity can significantly be increased (up to 50 times) by extrusion processing.

According to Ralet et al., paste formation is caused by solubilized pectic polymers [53]. Our results also demonstrate a correlation between paste viscosity and WSI. However, the WAI needs to be considered, too. Samples that take up more water swell more extensively, thereby increasing their specific volume. This leads to a larger excluded volume, which is not accessible by other particles. In consequence, there is less free volume (i.e., the dispersed volume fraction increases), resulting in an increased viscosity [56].

The paste-forming behavior of the samples can therefore be explained by increased water solubility and/or water absorption behavior. Extrusion disrupts the rigid cell wall structure (as described below), leading to a higher water uptake and swelling of the particles. At the same time, there is a larger number of soluble molecules (results of WSI see Section 3.2.1) in the direct neighborhood of dispersed particles, contributing to network formation.
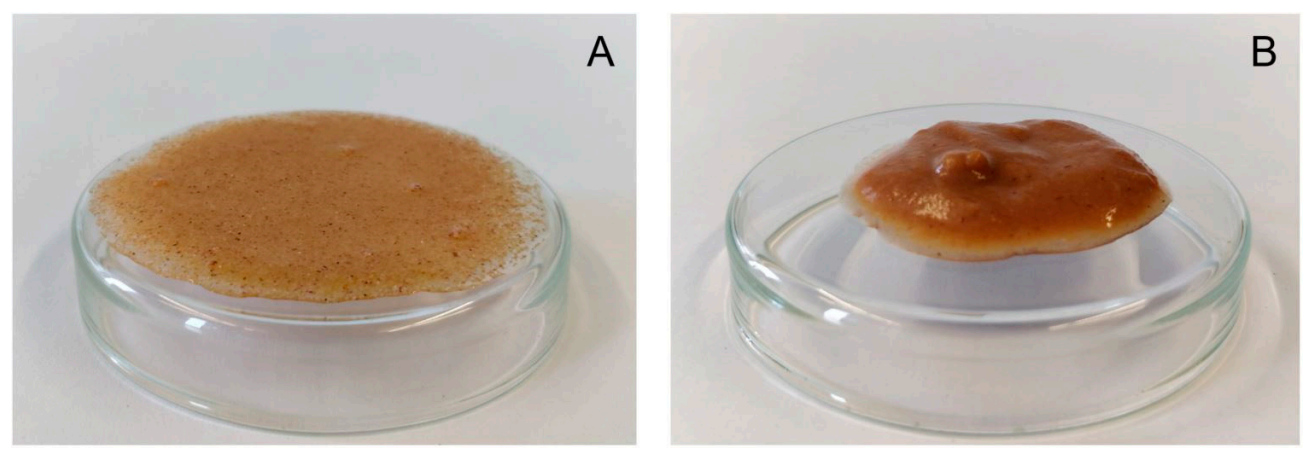

Figure 7. Water dispersions of $10 \%$ apple pomace powder extruded at $42 \%$ water content (A) and $17 \%$ water content $(\mathbf{B})$. Other extrusion processing conditions were kept constant $\left(200 \mathrm{~min}^{-1}\right.$, barrel temperature $\left.100{ }^{\circ} \mathrm{C}\right)$.

\subsubsection{Influence of Particle Size on Functional Properties}

With respect to functional properties, it is important to compare fractions that contain particles of similar size in order to avoid the influence of particle size on, for example, water absorption [57]. Therefore, all data presented so far were analyzed for a specific particle fraction $(0.14 \mathrm{~mm}<\mathrm{x}<$ $0.28 \mathrm{~mm}$ ). In contrast, it is assumed that industrial applications will utilize the entire sample and not a specific particle size fraction. Therefore, this study also analyzed the influence of extrusion processing on the structure and composition, as well as on the functional properties of the ground but non-sieved sample material. The particle size distribution was as follows: The percentage of particles with a particle size $<14 \mathrm{~mm}$ was $9-11 \%$, particle sizes $14-28 \mathrm{~mm}$ was $66-82 \%$ and particle size $>28 \mathrm{~mm}$ was $9-26 \%$. As sieving may result in the separation of specific sample components (starch, for example, may be enriched in fractions of smaller particle size), the influence of particle size on functional properties is presented below. However, based on the data presented so far, we analyzed only the samples with the most interesting functional properties (barrel temperature $100^{\circ} \mathrm{C}$; water content $22 \%$, and screw speeds of 200,450 , and $700 \mathrm{~min}^{-1}$ as well as water content of $42 \%$ and screw speed of $\left.200 \mathrm{~min}^{-1}\right)$. Hereafter, these samples will be designated as 100-42-200; 100-22-200; 100-22-450; and 100-22-700 (barrel temperature-water content-screw speed).

Figure 8 shows the WSI (A), WAI (B) and complex viscosity (C) of raw and extruded apple pomace comparing the entire, ground, non-sieved material with the sieved fraction that has been described so far.

The WSI of all samples with a defined particle size of $0.14-0.28 \mathrm{~mm}$ was higher compared to those of the entire (non-sieved) samples. The WSI of the sample extruded with a water content of $42 \%$ and a screw speed of $200 \mathrm{~min}^{-1}$ was lower than the WSI of the non-sieved raw material. For a water content 
of $22 \%$, the WSI increased with the screw speed also for the non-sieved samples. Although lower WSI values were observed for the entire sample as compared to the sieved fraction, the same trends were noted. The same holds true for the WAI (Figure 8B) and the complex viscosity (Figure 8C). However, when measuring the complex viscosity, non-sieved samples with low viscosity show a large standard deviation due to their broad particle size distribution.
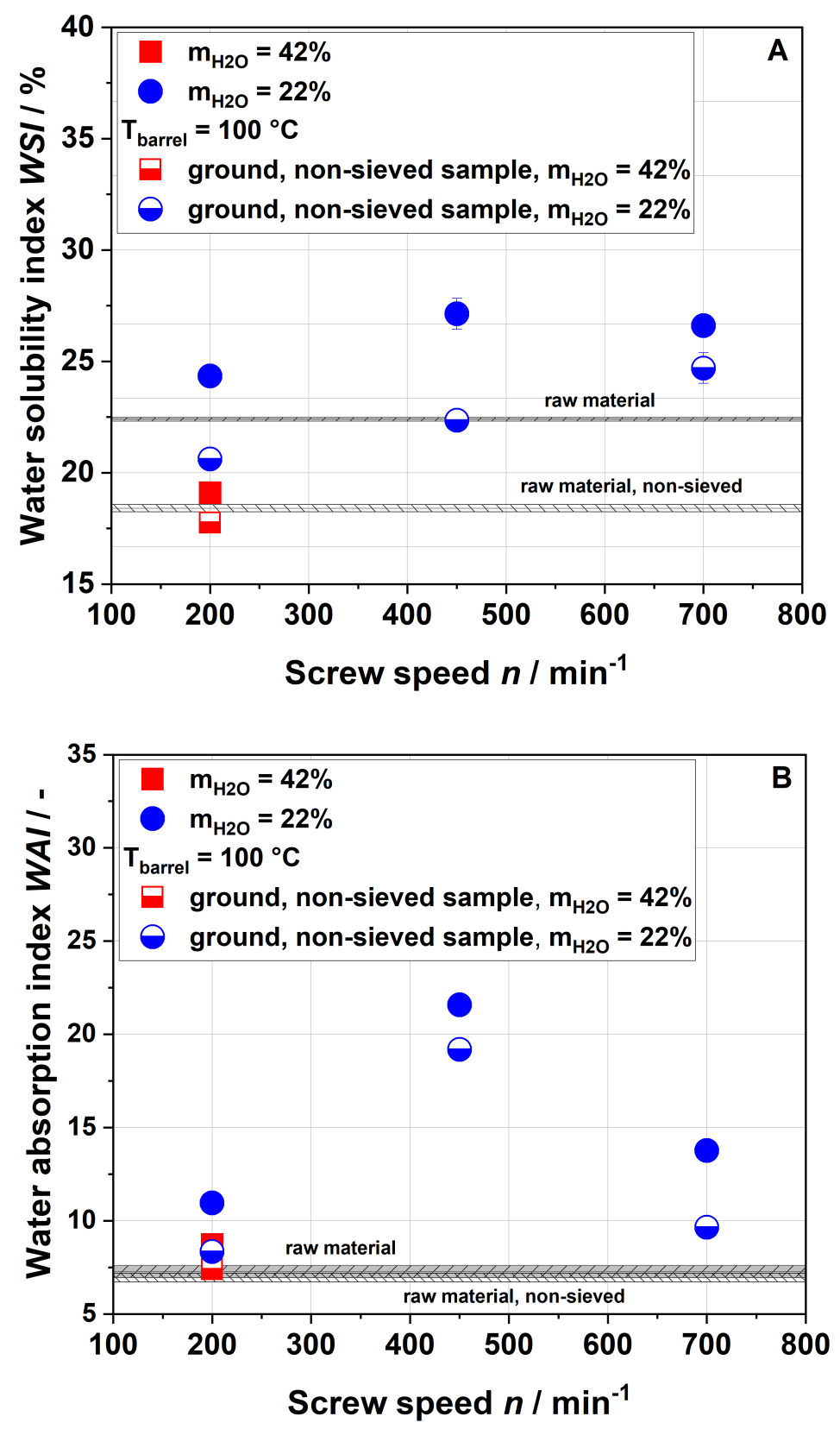

Figure 8. Cont. 


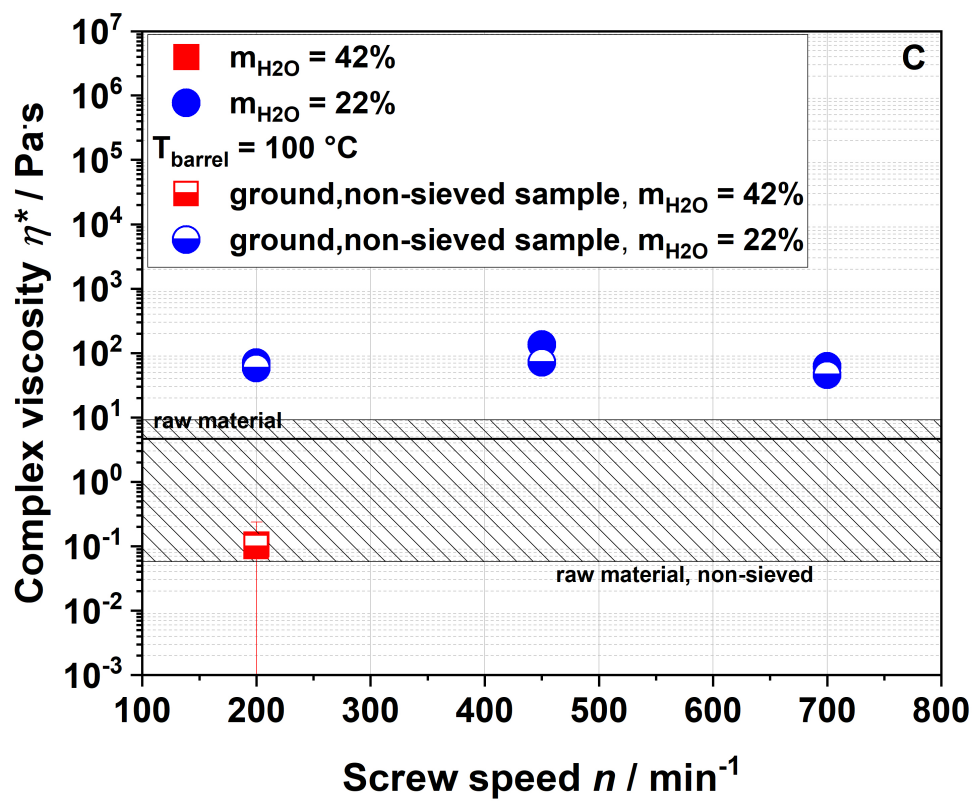

Figure 8. Water solubility index (A), water absorption index (B), and complex viscosity (C) of raw and extruded apple pomace for a particle fraction of $0.14-0.28 \mathrm{~mm}$ (filled) and the entire ground sample (half-filled).

\subsection{Impact of Extrusion on Molecular Structures}

The four samples 100-42-200, 100-22-200, 100-22-450 and 100-22-700 (see Section 3.2.5) were used to analyze the macroscopic and molecular structures of apple pomace before and after extrusion. To describe extrusion-based changes independently of the particle size and to characterize the application-relevant material, a detailed structural characterization was performed using the entire ground fraction as described in Section 3.2.5. However, to roughly check whether sieving has an impact on the polymer chemical composition, the monosaccharide composition of the polysaccharides of the sieved fraction (particle size of $0.14-0.28 \mathrm{~mm}$ ) was also determined (after both sulfuric acid hydrolysis and methanolysis). The data (Supporting Information, Table A1) did not indicate major compositional differences between the sieved and the non-sieved samples, disapproving the possibility that, for example, starch had been systematically sieved out due to the formation of smaller particles during grinding.

Protein, fat, ash content. The methods and data of the analysis of protein, fat and ash are given in the Supporting Information (Table A2) simply to characterize the raw material and extruded products. Below, we will focus on carbohydrates.

Free mono- and disaccharides. Because low-molecular weight compounds may also contribute to the physicochemical properties of the pomace, mono- and disaccharides were analyzed. Glucose, fructose, sucrose and maltose were detected and quantified as free mono- and disaccharides (Supporting Information, Table A3). The glucose content $(2.8 \pm 0.3 \mathrm{~g} / 100 \mathrm{~g}$ dry matter (DM)) did not change significantly during extrusion. In contrast, and as expected from the literature [58], the fructose content decreased with increasing thermo-mechanical treatment (from $8.8 \pm 0.3 \mathrm{~g} / 100 \mathrm{~g}$ DM to $3.4 \pm 0.1 \mathrm{~g} / 100 \mathrm{~g}$ DM (100-22-700)). Also, the sucrose content decreased from $2.3 \pm 0.4 \mathrm{~g} / 100 \mathrm{~g} \mathrm{DM}$ to $0.7 \pm 0.5 \mathrm{~g} / 100 \mathrm{~g} \mathrm{DM}(100-22-700)$, and maltose contents decreased independently of the extrusion conditions from $1.4 \pm 0.3 \mathrm{~g} / 100 \mathrm{~g}$ DM to below the limit of quantitation.

Starch. Depending on the stage of maturity, apples and thus apple pomace contain significant amounts of starch. The raw material contained $11.6 \pm 0.7 \mathrm{~g}$ starch $/ 100 \mathrm{~g}$ DM. Starch contents decreased to $8.5-9.2 \mathrm{~g} / 100 \mathrm{~g}$ DM during extrusion (Table A4, Supporting Information) with the decline being widely independent of the extrusion conditions. 
Dietary fiber composition. Insoluble dietary fiber contents decreased independently of the extrusion conditions (Table 1). Considering extrusion conditions using $22 \%$ water, soluble dietary fiber contents increased with increasing thermo-mechanical treatment. This trend was consistent with WSI data, although it needs to be considered that dietary fiber data exclude mono- and disaccharides, starch and protein, which are included in the WSI assay. Low-molecular-weight soluble dietary fiber was only formed at a screw speed of $700 \mathrm{~min}^{-1}$, which can easily be explained by extensive polymer degradation under high thermo-mechanical stress.

Table 1. Insoluble, soluble, and low-molecular-weight soluble dietary fiber contents ( $\mathrm{g} / 100 \mathrm{~g}$ dry matter) of raw and extruded apple pomace (mean value \pm standard deviation, $n=3$ ). For all samples, the barrel temperature was $100{ }^{\circ} \mathrm{C}$.

\begin{tabular}{|c|c|c|c|c|c|}
\hline & Raw Material & $100-42-200$ & $100-22-200$ & $100-22-450$ & $100-22-700$ \\
\hline Total content ${ }^{\mathrm{a}}$ & $67.6 \pm 1.7^{\mathrm{A}}$ & $60.7 \pm 1.8^{B}$ & $56.6 \pm 2.9^{C}$ & $60.1 \pm 1.7^{\mathrm{B}, \mathrm{C}}$ & $63.4 \pm 2.1^{\mathrm{A}, \mathrm{B}}$ \\
\hline Insoluble dietary fiber ${ }^{a}$ & $52.8 \pm 1.2^{\mathrm{A}}$ & $45.6 \pm 1.3^{B}$ & $43.5 \pm 1.9^{\mathrm{B}}$ & $43.3 \pm 1.0^{\mathrm{B}}$ & $45.4 \pm 0.6^{\mathrm{B}}$ \\
\hline Soluble dietary fiber ${ }^{\mathrm{a}}$ & $12.5 \pm 1.2^{\mathrm{A}}$ & $15.1 \pm 0.5^{\mathrm{A}}$ & $13.1 \pm 1.0^{\mathrm{B}, \mathrm{C}}$ & $16.8 \pm 0.7^{\mathrm{A}}$ & $16.7 \pm 1.3^{\mathrm{A}}$ \\
\hline $\begin{array}{c}\text { Low-molecular-weight } \\
\text { soluble fiber }\end{array}$ & - & - & - & - & $1.3 \pm 0.2$ \\
\hline
\end{tabular}

${ }^{a}$ Mean values within a row that are marked with different letters differ significantly $(p<0.05)$.

Unlike in the case of the WSI data and also in disagreement with the applied thermo-mechanical stress, the soluble dietary fiber content was higher for the 100-42-200 sample than for the 100-22-200 sample. A simple explanation is difficult to find; however, Maillard reaction products that are partially captured using the dietary fiber methodology might be at least one factor contributing to this unexpected finding.

The dietary fiber contents of apple pomace have been determined in the past [7,59]. According to the literature, insoluble and soluble fiber contents are dependent on the variety of apples (insoluble dietary fiber ranges between 33-67\%, soluble fiber between 3-14\%). The data analyzed here are within the range of the values found in the literature. Besides taking into account the variety, it needs to be considered that fiber contents and composition also depend on tissue maturity and changes during storage $[25,60]$. The influence of different extrusion parameters on fiber contents has been previously studied by Hwang and coworkers [32], who also found decreasing insoluble dietary fiber and increasing soluble fiber contents due to extrusion.

Polysaccharide characterization. Dietary fiber data indicate that thermo-mechanical treatment influences the structure of fiber polysaccharides, potentially going along with polymer solubilization and more or less specific degradation. This hypothesis is supported by data from the molecular weight distribution analysis. This analysis was used to assess the extent of structural changes of the soluble dietary fiber fraction rather than determining the exact molecular weight. Figure 9 shows that the molecular weight distribution became broader with increasing thermo-mechanical treatment, suggesting that large polymers had been (partially) broken down, thus backing up the dietary fiber composition data described above.

The monosaccharide compositions of insoluble fiber polysaccharides of raw material and extruded samples were determined after sulfuric acid hydrolysis (Table 2). Glucose was the main monomer $(43.4 \mathrm{~mol} \%)$ in the raw material, followed by arabinose $(17.3 \mathrm{~mol} \%)$, galacturonic acid $(11.9 \mathrm{~mol} \%)$, xylose $(11.0 \mathrm{~mol} \%)$ and galactose $(10.1 \mathrm{~mol} \%)$. The main portion of glucose could be attributed to cellulose, as well as being part of the hemicellulose xyloglucan. Xyloglucans, xylogalacturonans and secondary cell wall xylans are potential sources of xylose. Mannans are quantitatively less important in apple pomace insoluble fiber. The remaining monosaccharides could largely be assigned to pectic polymers (in total about $42 \mathrm{~mol} \%$ ) with arabinose and galactose being the most important units of rhamnogalacturonan I side chains, and galacturonic acid being a constituent of all pectic polysaccharides. It should be noted, however, that uronic acids are underestimated by using sulfuric 
acid hydrolysis. Overall, the insoluble dietary fiber monosaccharide composition was very similar to the recently published data of the composition of non-starch polysaccharides from apples after sulfuric acid hydrolysis [25].

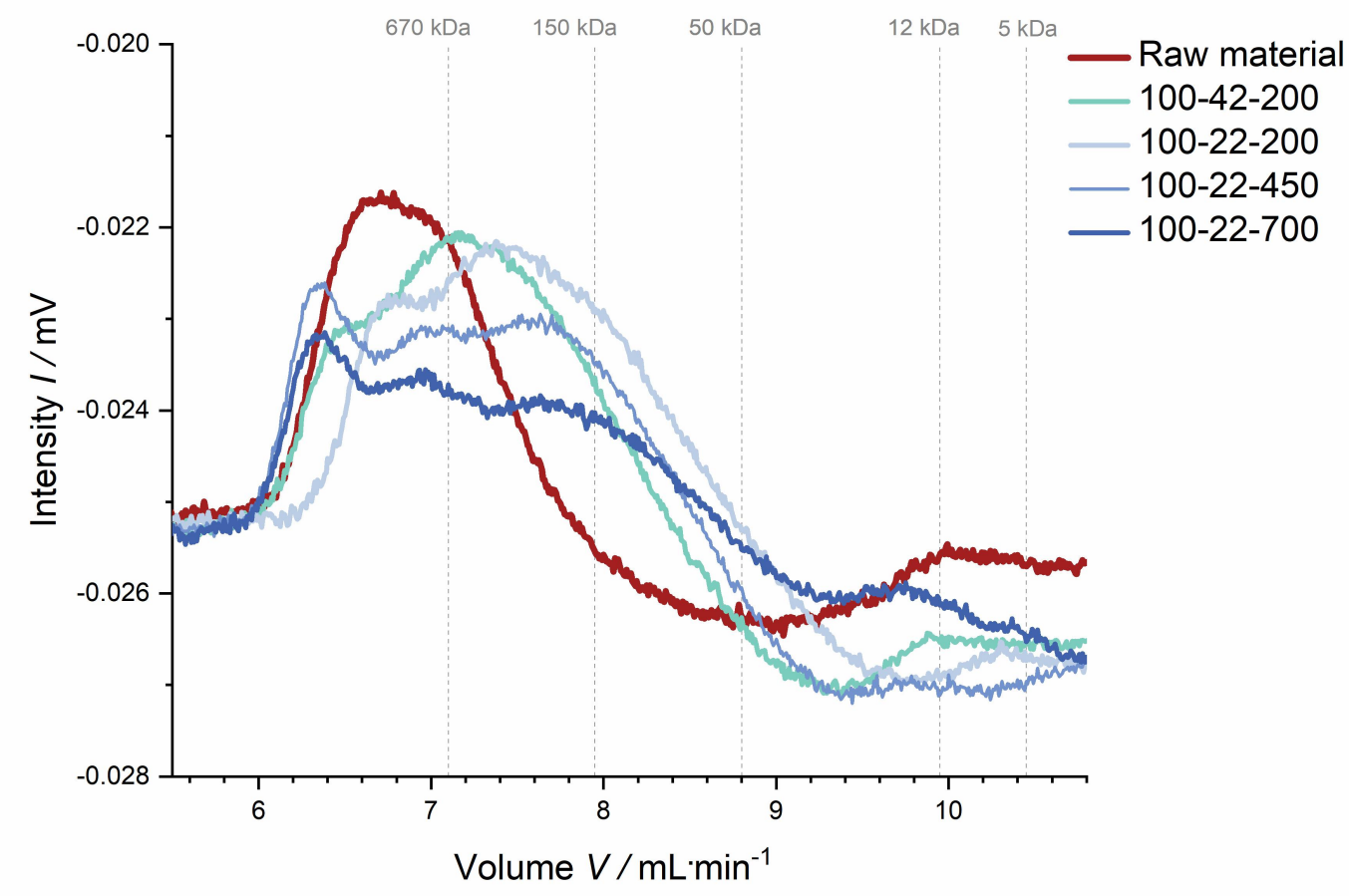

Figure 9. Molecular weight distribution of the soluble dietary fiber of raw and extruded apple pomace. The molecular weight distribution was determined by high-performance liquid chromatography with a refractive index detector. The intensity (refractive index detector signal) was plotted against the elution volume. Molecular weight calibration was performed by using dextrans (gray dotted lines).

Table 2. Monosaccharide composition ( $\mathrm{mol} \%$ ) of insoluble dietary fiber of raw and extruded apple pomace after sulfuric acid hydrolysis (mean value \pm range/2, $n=2$ ) Fuc: fucose, Rha: rhamnose, Ara: arabinose, Gal: galactose, Glc: glucose, Xyl: xylose, Man: mannose, GalA: galacturonic acid.

\begin{tabular}{cccccc}
\hline & Raw Material & $\mathbf{1 0 0 - 4 2 - 2 0 0}$ & $\mathbf{1 0 0 - 2 2 - 2 0 0}$ & $\mathbf{1 0 0 - 2 2 - 4 5 0}$ & $\mathbf{1 0 0 - 2 2 - 7 0 0}$ \\
\hline Fuc & $1.0 \pm 0.01$ & $\mathrm{a}$ & $\mathrm{a}$ & $\mathrm{a}$ & $\mathrm{a}$ \\
Rha & $2.3 \pm 0.05$ & $2.2 \pm 0.2$ & $1.6 \pm 0.01$ & $1.6 \pm 0.1$ & $1.5 \pm 0.1$ \\
Ara & $17.3 \pm 0.8$ & $15.6 \pm 0.3$ & $12.9 \pm 0.1$ & $10.3 \pm 0.2$ & $9.9 \pm 0.01$ \\
Gal & $10.1 \pm 0.2$ & $10.7 \pm 0.1$ & $11.5 \pm 0.4$ & $9.8 \pm 0.1$ & $11.0 \pm 0.2$ \\
Glc & $43.4 \pm 0.3$ & $47.1 \pm 0.5$ & $48.7 \pm 0.4$ & $52.9 \pm 0.3$ & $53.0 \pm 0.2$ \\
Xyl & $11.0 \pm 0.01$ & $11.4 \pm 0.03$ & $12.7 \pm 0.1$ & $13.7 \pm 0.5$ & $13.6 \pm 0.3$ \\
Man & $3.0 \pm 0.2$ & $2.8 \pm 0.1$ & $3.2 \pm 0.4$ & $3.8 \pm 0.2$ & $4.1 \pm 0.1$ \\
GalA & $11.9 \pm 0.8$ & $10.1 \pm 0.7$ & $9.3 \pm 0.4$ & $7.8 \pm 0.4$ & $6.9 \pm 0.1$ \\
\hline
\end{tabular}

${ }^{\text {a }}$ Below the limit of quantification.

The data of extruded samples indicate that insoluble fiber arabinose contents decreased by up to $7 \%$ (absolute) with increasing thermo-mechanical treatment, which is in agreement with the data published by Hwang et al. [32]. Also, the portion of galacturonic acid decreased in correlation with an increase in glucose and xylose.

The monosaccharide composition of apple pomace soluble dietary fiber polysaccharides was determined after methanolysis (Table 3). Not surprisingly, the constituents of pectic polysaccharides clearly dominated the soluble fiber fraction. Arabinose was the main monosaccharide $(42.0 \mathrm{~mol} \%)$, followed by galacturonic acid ( $32.9 \mathrm{~mol} \%)$ and galactose $(8.8 \mathrm{~mol} \%)$. Similarly to the insoluble dietary fiber polysaccharides, the amount of arabinose decreased by applying thermo-mechanical stress. 
However, unlike in the case of insoluble fiber, comparably weak thermo-mechanical treatment already had a distinct effect on arabinose portions, which were only slightly decreased with harsher treatment. Galactose and xylose containing polysaccharides appeared to be more stable, as indicated by the growing portions with harsher treatment.

Table 3. Monosaccharide composition ( $\mathrm{mol} \%$ ) of soluble dietary fiber of raw and extruded apple pomace after methanolysis (mean value \pm range/2,n=2) Fuc: fucose, Rha: rhamnose, Ara: arabinose, Gal: galactose, Glc: glucose, Xyl: xylose, Man: mannose, GlcA: glucuronic acid, GalA: galacturonic acid.

\begin{tabular}{|c|c|c|c|c|c|}
\hline & Raw Material & $100-42-200$ & $100-22-200$ & $100-22-450$ & $100-22-700$ \\
\hline Fuc & $\mathrm{a}$ & $\mathrm{a}$ & $\mathrm{a}$ & $0.7 \pm 0.04$ & $0.8 \pm 0.01$ \\
\hline Rha & $4.4 \pm 0.2$ & - & - & & \\
\hline Ara & $42.0 \pm 1.1$ & $34.6 \pm 3.1$ & $34.5 \pm 0.6$ & $33.0 \pm 0.8$ & $33.3 \pm 0.6$ \\
\hline Gal & $8.8 \pm 0.9$ & $11.0 \pm 1.4$ & $15.0 \pm 0.6$ & $16.1 \pm 0.4$ & $19.0 \pm 0.7$ \\
\hline Glc & $4.7 \pm 1.4$ & $4.5 \pm 0.1$ & $4.4 \pm 0.8$ & $3.4 \pm 0.3$ & $4.1 \pm 0.1$ \\
\hline Xyl & $1.7 \pm 0.3$ & $2.3 \pm 2.3$ & $3.6 \pm 0.2$ & $3.8 \pm 0.6$ & $5.8 \pm 0.05$ \\
\hline Man & $4.7 \pm 0.7$ & $1.1 \pm 1.1$ & $1.6 \pm 0.1$ & $1.1 \pm 0.1$ & $1.4 \pm 0.1$ \\
\hline GalA & $32.9 \pm 0.4$ & $44.6 \pm 2.6$ & $39.4 \pm 1.3$ & $40.4 \pm 0.7$ & $34.1 \pm 1.2$ \\
\hline GlcA & $0.8 \pm 0.05$ & $1.7 \pm 0.1$ & $1.6 \pm 0.1$ & $1.4 \pm 0.1$ & $1.5 \pm 0.1$ \\
\hline
\end{tabular}

${ }^{a}$ Below the limit of quantification.

However, these data and additional structural data have to be interpreted keeping in mind two mechanisms of how the compositions of the soluble and insoluble dietary fiber preparations can be altered: 1) solubilization of formerly insoluble polysaccharides, shifting them into the soluble fiber fraction, and 2) actual decomposition of specific structural units in the insoluble or soluble fiber fraction. Also, carbohydrates may be degraded or converted into Maillard products, thus escaping our analyses. As these mechanisms occur simultaneously, definite conclusions are sometimes difficult to draw.

The low-molecular-weight soluble dietary fiber that was produced in the 100-22-700 was mainly composed of arabinose and galactose (35.9\% and $18.2 \%)$, respectively, and, surprisingly, glucose (41.8\%). Xylose $(0.9 \%)$ and mannose $(3.1 \%)$ were only minor constituents.

Methylation analysis of the insoluble dietary fiber fraction showed that glucose was mainly a constituent of cellulose (1,4-linked) with lower portions being involved in xyloglucans (1,4,6-linked; 1,4-linked) (Table 4). 1,2-Linked xylopyranose units may have occurred as side chains of xyloglucans. Terminal xylopyranose could be assigned to both xyloglucans and xylans. However, low amounts of 1,4-linked xylopyranose $(1.9 \mathrm{~mol} \%)$ suggested small amounts of xylans as secondary cell wall components only. The identification of mannose after sulfuric acid hydrolysis and low levels of 1,4-linked mannopyranose and 1,4,6-linked mannopyranose demonstrated the existence of (partially branched) mannans in the insoluble fiber fraction. Methylation analysis confirmed that arabinose was mostly integrated in arabinans (1,5-linked) with branches in position $\mathrm{O}-2, \mathrm{O}-3$, or in both positions (1,2,5-, 1,3,5- and 1,2,3,5- linked arabinofuranose units). Branches in position $O-3$ dominated over branches in position $\mathrm{O}-2$, as previously demonstrated by Wefers, Flörchinger et al. [25], and doubly substituted arabinose units were quite common. Galactans were mostly unsubstituted (1,4-linked). Methylation analysis data demonstrated the impact of extrusion on insoluble fiber polysaccharides, confirming assumptions made from the analysis of the monosaccharide composition. Changes were most obvious in samples treated at a screw speed of $700 \mathrm{~min}^{-1}$ : terminal arabinofuranose and 1,3,5-linked arabinofuranose portions were distinctly decreased. Also, doubly substituted arabinan units were decreased using the harshest extrusion conditions. Comparable observations were also made by Schmid et al. [61], who studied thermo-mechanically treated aronia pomace. Galactans, which are often difficult to fully capture using methylation analysis, did not show a clear extrusion affected behavior. 
Table 4. Glycosidic linkages (partially methylated alditol acetates; mol\%) of insoluble dietary fiber of raw and extruded apple pomace (mean value \pm range/2, $n=2$ ). t: terminal, $p$ : pyranose, $f$ : furanose, Rha: rhamnose, Ara: arabinose, Gal: galactose, Glc: glucose, Man: mannose, Xyl: xylose.

\begin{tabular}{|c|c|c|c|c|c|}
\hline & Raw Material & $100-42-200$ & $100-22-200$ & $100-22-450$ & $100-22-700$ \\
\hline 1,2-Rhap & $0.8 \pm 0.1$ & $0.4 \pm 0.1$ & $0.4 \pm 0.1$ & $0.6 \pm 0.1$ & $0.8 \pm 0.2$ \\
\hline 1,2,4-Rhap & $0.4 \pm 0.1$ & $0.4 \pm 0.1$ & $0.4 \pm 0.1$ & $0.4 \pm 0.1$ & $0.6 \pm 0.3$ \\
\hline$\sum$ Rha & $1.2 \pm 0.2$ & $0.8 \pm 0.2$ & $0.8 \pm 0.3$ & $1.0 \pm 0.2$ & $1.4 \pm 0.5$ \\
\hline $\mathrm{t}$-Araf & $13.5 \pm 2.7$ & $8.9 \pm 1.0$ & $8.6 \pm 1.0$ & $7.1 \pm 0.1$ & $8.4 \pm 1.2$ \\
\hline t-Arap & a & $1.5 \pm 1.1$ & $1.5 \pm 1.0$ & $0.5 \pm 0.1$ & $1.2 \pm 0.2$ \\
\hline 1,5-Araf/1,4-Ara $p$ & $8.4 \pm 0.04$ & $8.9 \pm 1.1$ & $8.6 \pm 1.0$ & $9.0 \pm 2.1$ & $11.2 \pm 2.7$ \\
\hline 1,3-Araf & a & $1.2 \pm 0.03$ & $1.2 \pm 0.03$ & $0.9 \pm 0.2$ & $1.6 \pm 0.1$ \\
\hline $1,2,5$-Araf & $1.2 \pm 0.1$ & $1.6 \pm 0.4$ & $1.5 \pm 0.3$ & $1.3 \pm 0.2$ & $1.0 \pm 0.1$ \\
\hline $1,3,5$-Araf & $4.3 \pm 0.3$ & $2.8 \pm 0.2$ & $2.7 \pm 0.2$ & $1.5 \pm 0.2$ & $1.2 \pm 0.7$ \\
\hline 1,2,3,5-Araf & $6.6 \pm 0.5$ & $8.8 \pm 1.1$ & $8.5 \pm 1.0$ & $5.1 \pm 1.6$ & $4.1 \pm 0.1$ \\
\hline$\sum$ Ara & $34.0 \pm 3.6$ & $33.6 \pm 4.8$ & $32.6 \pm 4.7$ & $25.5 \pm 4.4$ & $28.6 \pm 5.0$ \\
\hline $\mathrm{t}-\mathrm{Gal} p$ & $2.9 \pm 0.3$ & $2.8 \pm 0.3$ & $2.7 \pm 0.3$ & $2.7 \pm 0.03$ & $4.1 \pm 0.3$ \\
\hline 1,4-Galp & $3.1 \pm 0.1$ & $2.6 \pm 0.3$ & $2.5 \pm 0.3$ & $2.4 \pm 0.1$ & $3.9 \pm 0.1$ \\
\hline 1,6-Galp & $0.3 \pm 0.1$ & $0.3 \pm 0.03$ & $0.3 \pm 0.03$ & $0.6 \pm 0.05$ & $1.2 \pm 0.01$ \\
\hline$\sum \mathrm{Gal}$ & $6.3 \pm 0.6$ & $5.7 \pm 0.6$ & $5.5 \pm 0.6$ & $5.7 \pm 0.2$ & $9.1 \pm 0.4$ \\
\hline $\mathrm{t}-\mathrm{Glc} p$ & $1.2 \pm 0.04$ & $1.3 \pm 0.3$ & $1.3 \pm 0.3$ & $1.7 \pm 0.2$ & $1.8 \pm 0.4$ \\
\hline 1,4-Glcp & $35.8 \pm 4.2$ & $33.8 \pm 0.6$ & $32.8 \pm 0.4$ & $36.8 \pm 1.6$ & $24.9 \pm 1.7$ \\
\hline 1,4,6-Glc $p$ & $5.7 \pm 1.4$ & $8.2 \pm 1.0$ & $8.6 \pm 1.0$ & $9.9 \pm 0.1$ & $5.6 \pm 2.4$ \\
\hline$\sum$ Glc & $42.7 \pm 5.7$ & $42.1 \pm 1.6$ & $42.7 \pm 1.7$ & $48.4 \pm 1.9$ & $32.3 \pm 4.5$ \\
\hline 1,4-Man $p$ & $2.9 \pm 0.8$ & $2.9 \pm 0.4$ & $2.9 \pm 0.4$ & $2.9 \pm 0.1$ & $4.5 \pm 0.1$ \\
\hline 1,4,6-Man $p$ & $0.5 \pm 0.2$ & a & a & $\mathrm{a}$ & $\mathrm{a}$ \\
\hline$\sum$ Man & $3.4 \pm 1.0$ & $2.9 \pm 0.4$ & $2.9 \pm 0.4$ & $2.9 \pm 0.1$ & $4.5 \pm 0.1$ \\
\hline $\mathrm{t}-\mathrm{Xyl} p$ & $7.8 \pm 0.6$ & $9.2 \pm 0.7$ & $8.9 \pm 0.7$ & $8.7 \pm 0.5$ & $12.7 \pm 0.3$ \\
\hline $1,2-\mathrm{Xyl} p^{\mathrm{b}}$ & $2.7 \pm 0.5$ & $2.3 \pm 0.2$ & $3.0 \pm 0.1$ & $3.8 \pm 0.4$ & $6.0 \pm 0.1$ \\
\hline $1,4-X y l p^{b}$ & $1.9 \pm 0.2$ & $2.0 \pm 0.03$ & $3.5 \pm 0.4$ & $4.0 \pm 0.3$ & $5.4 \pm 0.7$ \\
\hline$\sum \mathrm{Xyl}$ & $12.4 \pm 1.4$ & $13.5 \pm 0.9$ & $15.4 \pm 1.2$ & $16.6 \pm 1.2$ & $24.0 \pm 1.2$ \\
\hline
\end{tabular}

${ }^{a}$ Not detected; ${ }^{\mathrm{b}}$ Coeluting, determined from the area ratio of the characteristic fragment ion peaks. 1,2-Xyl $p: \mathrm{m} / \mathrm{z}$ 117, 1,4-Xylp: $m / z 118$.

To confirm the methylation analysis data on arabinans and galactans, an arabinan and galactan screening was performed according to the method described by Wefers, Bunzel et al. [45]. Using endo-arabinanases and endo-galactanases, linear $\alpha-(1 \rightarrow 5)$-linked regions within the arabinan backbone and $\beta-(1 \rightarrow 4)$-linked regions within the galactan backbone were cleaved, releasing oligomeric units (Table 5, for structures see Figure A1 in the Supporting Information). The results did not fully support methylation analysis data with regard to O-3-linked structural units (as mostly reflected by compound A-4a), but also showed a decrease in doubly substituted arabinan structural elements (as reflected by A5a) and generally demonstrated that arabinan complexity was reduced with the application of thermo-mechanical stress. The galactan screening assay confirmed the existence of galactans but did not reveal additional structural data. Xylans, as reflected by 1,4-linked xylopyranose units in the methylation analysis, appeared to be more stable during extrusion and were enriched in the 100-22-700 sample.

Methylation analysis of the soluble dietary fiber fraction confirmed the dominance of the arabinan building blocks among the neutral monosaccharides. Just as seen for the insoluble fiber fraction, branches in position $O-3$ dominated over branches in position $O-2$, and doubly substituted arabinose units were shown to be important structural features in apple pomace soluble fiber. Most distinct effects were seen when the harshest extrusion conditions were applied (100-22-700). Again, the portion of terminal arabinose units was strongly reduced; however, the effect on 1,3,5- (and 1,2,3,5-) linked arabinose units was negligible. Although the changes were minor, xyloglucans may have been enriched 
in this extruded sample as compared to the raw material. Application of the enzymatic arabinan and galactan profiling assay confirmed the existence of the structural units determined by using methylation analysis (Tables A5 and A6, Supporting Information) but did not reveal any additional information with respect to the stability of structural units against thermo-mechanical stress.

Table 5. Arabinan and galactan oligosaccharide composition ( $\mathrm{mol} \%$ ) after incubation of insoluble dietary fiber of raw and extruded apple pomace with endo-arabinanase and endo-galactanase (mean value \pm range $/ 2, n=2$ ).

\begin{tabular}{cccccc}
\hline Compound & Raw Material & $\mathbf{1 0 0 - 4 2 - 2 0 0}$ & $\mathbf{1 0 0 - 2 2 - 2 0 0}$ & $\mathbf{1 0 0 - 2 2 - 4 5 0}$ & $\mathbf{1 0 0 - 2 2 - 7 0 0}$ \\
\hline \multicolumn{7}{c}{ Arabinan oligosaccharide } \\
A-2a & $84.0 \pm 0.4$ & $84.2 \pm 0.3$ & $87.6 \pm 0.05$ & $83.5 \pm 0.8$ & $83.8 \pm 0.1$ \\
A-4a & $7.2 \pm 0.4$ & $10.5 \pm 0.05$ & $10.2 \pm 0.1$ & $11.9 \pm 0.8$ & $11.1 \pm 0.2$ \\
A-4b & - & $1.7 \pm 0.1$ & $1.1 \pm 0.01$ & $2.2 \pm 0.1$ & $2.0 \pm 0.3$ \\
A-5a & $4.1 \pm 0.02$ & $1.3 \pm 0.1$ & $1.0 \pm 0.1$ & $0.7 \pm 0.1$ & $1.1 \pm 0.1$ \\
A-5b & $2.1 \pm 0.1$ & $2.4 \pm 0.1$ & - & $1.7 \pm 0.1$ & $2.0 \pm 0.03$ \\
A-5c & $0.7 \pm 0.1$ & - & - & - & - \\
A-7a & $1.9 \pm 0.1$ & - & - & - & - \\
\hline G-2a & $98.3 \pm 0.3$ & Galactan oligosaccharide & 100.0 \\
G-2b & - & 100.0 & 100.0 & - \\
G-2c & $1.7 \pm 0.3$ & - & a & a & a \\
\hline \multicolumn{7}{c}{ a Below the limit of quantification. }
\end{tabular}

The degree of esterification of polymer-bound galacturonic acid affects gel formation depending on the gel formation mechanism used. Our data suggest that thermo-mechanical stress reduced the degree of esterification, as clearly demonstrated for the insoluble dietary fiber fraction: the degree of esterification decreased with increasing screw speed from 50\% (raw material) to 15\% (100-22-700). Comparable behavior was observed for soluble dietary fiber pectic polysaccharides. Modifications with acetates appeared to be more stable than with methyl esters; however, a reduction of the acetylation degree in the extruded samples was observed for the insoluble dietary fiber pectic polysaccharides.

\subsection{Influence of Process Conditions on Surface and Porosity}

The surfaces of raw apple pomace (left: A, B) and extruded apple pomace (right: C, D) were visualized by SEM (Zeiss LEO1530). Two representative photographs were selected for both samples and compared in Figure 10.

Figure 10A,B show a rigid closed surface structure of the raw material, whereas the ruptured surface structure of the extruded sample can be seen in Figure 10C,D. Apparently, extrusion disrupted and altered the macroscopic structure of cell walls, resulting in more porous structures.

Therefore, the pore structure of the sieved samples was further analyzed by using a staining technique. Using two different dyes, the pore size distribution and thus the accessible surface area, where dyes could adsorb, could be determined. Direct Yellow 4 (DY 4) populated smaller pores (total accessible surface for molecules: $542 \AA^{2}$, volume: $548 \AA^{3}$ ), whereas Direct Red 28 (DR 28) populated larger pores (surface: $539 \AA^{2}$, volume: $526 \AA^{3}$ ) [62].

Compared to measurements of dry powder by BET, staining methods reflected pore structures in the hydrated state, which is relevant to the water absorption and gelling behavior. Table 6 shows the absorbance of the dye DY 4 and DR 28 by the raw material and the extruded samples, which are characterized in detail in Section 3.3.

With decreasing water content during extrusion and increasing screw speed, the sample absorbed more DY 4 dye and less DR 28. Due to their different sizes, it can be concluded that extrusion processing can lead to more small pores, which can be infiltrated by DY 4. 
These results suggest that the surface area and porosity are increased by thermo-mechanical treatment during extrusion. Concurrently, water might infiltrate more easily into the cell walls and contribute to the dissolution of the soluble fraction.
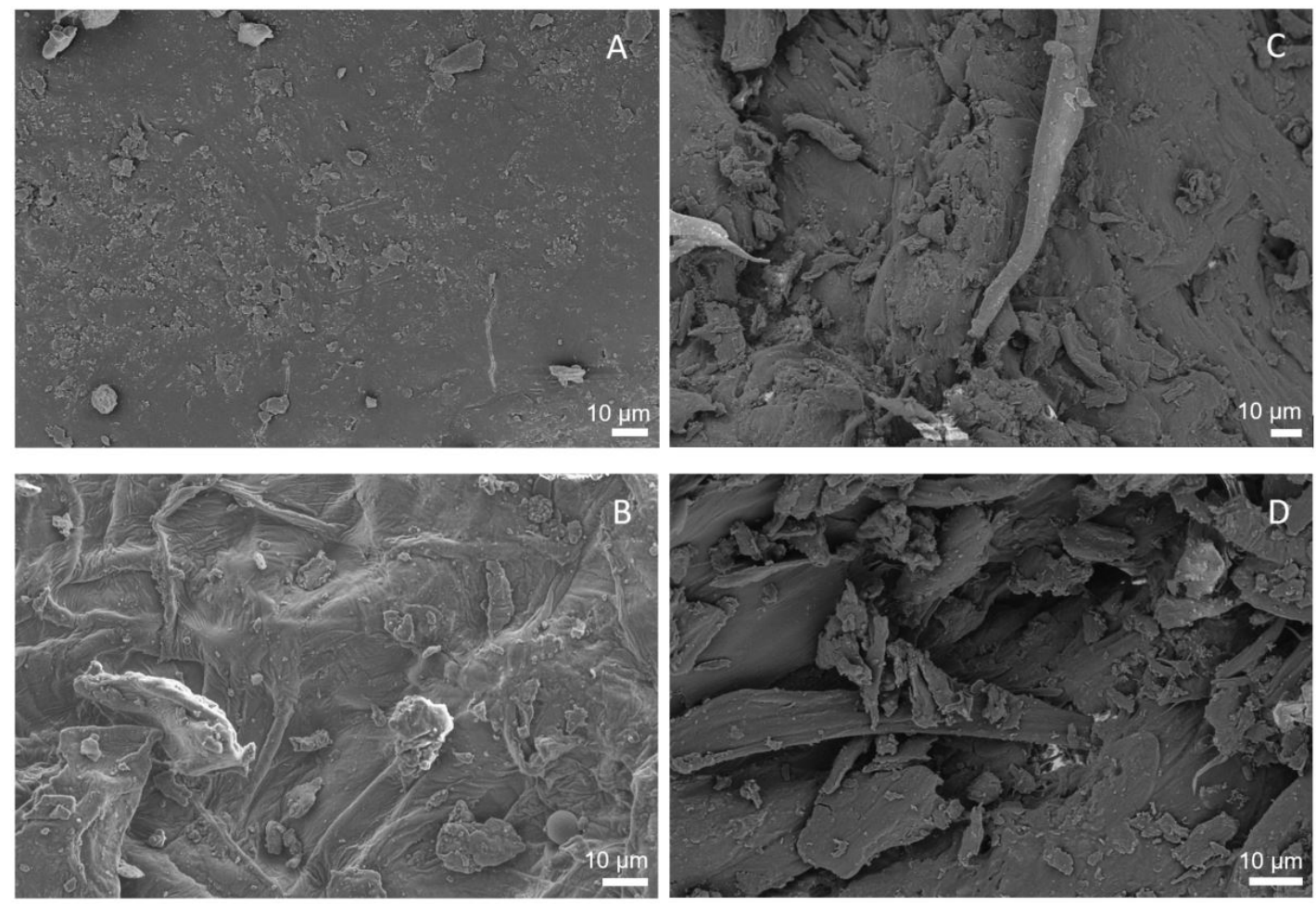

Figure 10. Scanning electron microscope photographs of apple pomace surfaces. (A,B) show the raw material. (C,D) show the surface of apple pomace extruded at $T_{\text {barrel }}=100{ }^{\circ} \mathrm{C}$ and a water content of $17 \%$, using a screw speed of $200 \mathrm{~min}^{-1}(100-17-200)$.

Table 6. Absorption of DY 4 and DR 28 of raw material and various extruded apple pomace samples for a barrel temperature of $100{ }^{\circ} \mathrm{C}$.

\begin{tabular}{ccc}
\hline & $\begin{array}{c}\text { Absorbed Direct Yellow 4 } \\
{\left[\mathbf{m g}_{\text {dye }} \cdot \mathbf{g}_{\text {sample }} \mathbf{- 1}^{\mathbf{1}}\right]}\end{array}$ & $\begin{array}{c}\text { Absorbed Direct Red 28 } \\
{\left[\mathbf{m g}_{\text {dye }} \cdot \mathbf{g}_{\text {sample }} \mathbf{~}^{\mathbf{1}} \text { ] }\right.}\end{array}$ \\
\hline raw material & $5.541 \pm 0.013$ & $9.827 \pm 0.018$ \\
$100-42-200$ & $6.208 \pm 0.009$ & $9.815 \pm 0.011$ \\
$100-22-200$ & $6.749 \pm 0.007$ & $9.732 \pm 0.010$ \\
$100-22-450$ & $6.712 \pm 0.009$ & $8.809 \pm 0.006$ \\
$100-22-700$ & $6.876 \pm 0.014$ & $8.103 \pm 0.003$ \\
\hline
\end{tabular}

\section{Conclusions}

This study shows that valuable residues like apple pomace can be modified and functionalized by extrusion processing. The analysis of the functional properties shows that water solubility increased up to $33 \%$, water absorption up to $22 \%$ and paste viscosity up to 20 times for the highest thermo-mechanical treatment $\left(n=700 \mathrm{~min}^{-1}, m_{\mathrm{H} 2 \mathrm{O}}=17 \%\right)$ applied. The increase in viscosity was the most prominent modification of the extruded samples. The extent of the thermo-mechanical treatment could be varied significantly by reducing the water content, which was identified to be the main influencing parameter to alter the hydration properties and viscosity of aqueous apple pomace dispersions.

The analysis of the structural components showed changes with increasing thermo-mechanical treatment: a decrease in insoluble dietary fiber as well as an increase in soluble dietary fiber up to low-molecular soluble dietary fiber at maximum screw speed $\left(n=700 \mathrm{~min}^{-1}, m_{\mathrm{H} 2 \mathrm{O}}=22 \%\right)$ was observed. More precisely, a decrease in arabinose and also galacturonic acid constituents in the 
insoluble dietary fiber was measured, indicating solubilization or degradation of previously insoluble pectic polysaccharides during extrusion. The SEM images and Simons' stain results showed that extrusion not only induced modifications on a molecular level, but also affected macromolecular structures, thus increasing the porosity of the samples, which may explain the increase in WAI. These trends were independent of the particle size of the extruded material, suggesting that the entire material after grinding can be used for applications in foods, e.g., bread, instead of using a specific particle size fraction only.

Nevertheless, to adjust the techno-functional properties according to the desired and specific needs, it is necessary to control the functionalization of apple pomace during the extrusion process more closely. Thus, further studies on the individual and defined effects of both thermal and mechanical stresses on structural changes on a microscopic and molecular level and related techno-functionality are needed.

Author Contributions: V.S.: Data curation, Project administration, Methodology, Writing—original draft, Writing - review \& editing, Investigation, Visualization. A.T.: Data curation, Methodology, Investigation, Visualization, Writing — original draft. J.S.: Project administration, Methodology, Supervision, Writing — Review \& editing. M.B.: Conceptualization, Funding acquisition, Project administration, Resources, Supervision, Writing-Review \& editing. H.P.K.: Funding acquisition, Recources, Writing—review \& editing. M.A.E.: Project administration, Funding acquisition, Conceptualization, Supervision, Resources, Writing-Review \& editing. All authors have read and agreed to the published version of the manuscript.

Funding: The IGF research project $(20518 \mathrm{~N})$ of the FEI was supported via AiF within the program for promoting the Industrial Collective Research (IGF) of the German Ministry of Economics and Energy (BMWi), bases on a resolution of German Parliament.

Acknowledgments: The authors would like to express their thanks to Kerstin Sauther, Andrea Butterbrodt, Felix Ellwanger, Svenja Eppinger, Gizem Özcan, and Lena Trapp for supporting the sample preparation and analyses, Herbafood Ingredients GmbH for providing the apple pomace, and LEM (KIT) for supporting us with SEM pictures. Furthermore, the authors acknowledge support by the KIT-Publication Fund of the Karlsruhe Institute of Technology.

Conflicts of Interest: The authors declare that they have no known competing financial interests or personal relationships that could have appeared to influence the work reported in this paper.

\section{Appendix A}

\section{Appendix A.1. Supporting Methods}

Protein content. Sample material (100 mg) was digested by using the Kjedahl approach, and ammonia detection was performed using an ammonia electrode [41].

Fat content. Sample material (5-10 g) was weighed into a fat-free extraction tube and extracted in a Soxleth apparatus for $1 \mathrm{~h} 22 \mathrm{~min}$ using petroleum ether as solvent.

Ash content. Sample material $(1 \mathrm{~g})$ was weighed into a crucible. After incineration at $500{ }^{\circ} \mathrm{C}$ for $4 \mathrm{~h}$, the ash content was determined gravimetrically. 
Appendix A.2. Supporting Tables

Table A1. Monosaccharide composition (mol\%) of the polysaccharides of the sieved and non-sieved fraction of apple pomace (raw and extruded) after sulfuric acid hydrolysis and methanolysis (mean value \pm range/2, $n=2$ ). Ara: arabinose, Gal: galactose, Glc: glucose, Xyl: xylose, Man: mannose, GalA: galacturonic acid, Rha: rhamnose, GlcA: glucuronic acid.

\begin{tabular}{|c|c|c|c|c|c|c|c|c|c|c|}
\hline \multicolumn{11}{|c|}{ Sulfuric Acid Hydrolysis } \\
\hline & \multicolumn{2}{|c|}{ Raw Material } & \multicolumn{2}{|c|}{$100-42-200$} & \multicolumn{2}{|c|}{$100-22-200$} & \multicolumn{2}{|c|}{$100-22-450$} & \multicolumn{2}{|c|}{$100-22-700$} \\
\hline & Sieved & Non-sieved & Sieved & Non-sieved & Sieved & Non-sieved & Sieved & Non-sieved & Sieved & Non-sieved \\
\hline Ara & $16.4 \pm 0.3$ & $15.1 \pm 0.3$ & $16.1 \pm 0.05$ & $16.1 \pm 0.03$ & $15.8 \pm 0.2$ & $16.1 \pm 0.1$ & $16.4 \pm 0.1$ & $16.3 \pm 0.1$ & $16.1 \pm 0.4$ & $15.9 \pm 0.2$ \\
\hline Gal & $10.1 \pm 0.4$ & $9.4 \pm 0.5$ & $10.7 \pm 0.4$ & $9.4 \pm 0.5$ & $10.7 \pm 0.1$ & $9.9 \pm 0.02$ & $14.4 \pm 0.2$ & $13.1 \pm 0.3$ & $15.0 \pm 0.2$ & $13.6 \pm 1.1$ \\
\hline Glc & $43.1 \pm 1.1$ & $45.4 \pm 0.6$ & $44.0 \pm 0.1$ & $42.5 \pm 0.2$ & $43.5 \pm 0.4$ & $42.0 \pm 0.6$ & $44.1 \pm 0.1$ & $42.5 \pm 0.2$ & $43.8 \pm 0.01$ & $44.5 \pm 1.6$ \\
\hline Xyl & $7.1 \pm 0.2$ & $8.0 \pm 0.3$ & $7.0 \pm 0.2$ & $8.0 \pm 0.3$ & $7.0 \pm 0.06$ & $8.1 \pm 0.5$ & $7.8 \pm 0.1$ & $8.0 \pm 0.2$ & $7.4 \pm 0.1$ & $8.7 \pm 0.1$ \\
\hline Man & $2.5 \pm 0.1$ & $2.5 \pm 0.2$ & $2.6 \pm 0.1$ & $2.1 \pm 0.04$ & $2.2 \pm 0.1$ & $2.1 \pm 0.01$ & $2.3 \pm 0.01$ & $2.2 \pm 0.2$ & $2.3 \pm 0.1$ & $2.5 \pm 0.2$ \\
\hline GalA & $20.8 \pm 0.2$ & $19.6 \pm 0.8$ & $19.6 \pm 0.8$ & $21.2 \pm 0.2$ & $20.9 \pm 0.03$ & $22.3 \pm 0.2$ & $18.6 \pm 0.03$ & $21.1 \pm 0.3$ & $18.3 \pm 0.9$ & $16.2 \pm 1.9$ \\
\hline \multicolumn{11}{|c|}{ Methanolysis } \\
\hline Rha & $2.1 \pm 0.1$ & $2.3 \pm 0.05$ & $2.0 \pm 0.2$ & $1.9 \pm 0.05$ & $1.6 \pm 0.3$ & $1.7 \pm 0.001$ & $1.6 \pm 0.01$ & $1.5 \pm 0.2$ & $1.4 \pm 0.3$ & $1.4 \pm 0.3$ \\
\hline Ara & $23.2 \pm 0.5$ & $23.8 \pm 0.1$ & $25.6 \pm 0.6$ & $22.5 \pm 0.1$ & $22.3 \pm 0.9$ & $22.1 \pm 0.6$ & $22.7 \pm 0.9$ & $22.0 \pm 0.2$ & $23.1 \pm 1.5$ & $24.3 \pm 2.0$ \\
\hline Gal & $13.5 \pm 0.4$ & $14.2 \pm 0.2$ & $15.0 \pm 0.3$ & $13.1 \pm 0.3$ & $13.0 \pm 0.2$ & $13.3 \pm 0.3$ & $14.4 \pm 0.2$ & $13.1 \pm 0.3$ & $15.0 \pm 0.2$ & $13.6 \pm 1.1$ \\
\hline Gluc & $12.9 \pm 0.5$ & $13.7 \pm 0.5$ & $14.4 \pm 0.3$ & $15.1 \pm 0.2$ & $14.6 \pm 0.3$ & $15.4 \pm 0.05$ & $15.7 \pm 0.04$ & $15.8 \pm 0.2$ & $14.5 \pm 0.2$ & $14.0 \pm 0.1$ \\
\hline Xyl & $11.5 \pm 0.3$ & $12.8 \pm 0.2$ & $11.9 \pm 0.6$ & $12.5 \pm 0.1$ & $13.4 \pm 0.3$ & $13.5 \pm 0.004$ & $11.7 \pm 0.4$ & $11.8 \pm 0.4$ & $11.9 \pm 0.4$ & $10.9 \pm 0.5$ \\
\hline Man & $1.4 \pm 0.1$ & $1.2 \pm 0.01$ & $1.3 \pm 0.003$ & $1.5 \pm 0.1$ & $1.7 \pm 0.2$ & $1.7 \pm 0.1$ & $1.6 \pm 0.1$ & $1.5 \pm 0.3$ & $1.5 \pm 0.1$ & $1.3 \pm 0.3$ \\
\hline GalA & $35.0 \pm 0.8$ & $31.5 \pm 0.7$ & $29.9 \pm 0.8$ & $32.9 \pm 0.6$ & $32.8 \pm 0.5$ & $31.9 \pm 0.2$ & $31.9 \pm 0.7$ & $33.8 \pm 0.7$ & $31.9 \pm 1.4$ & $33.7 \pm 2.4$ \\
\hline GlcA & $0.4 \pm 0.01$ & $0.5 \pm 0.02$ & & $0.5 \pm 0.03$ & $0.6 \pm 0.1$ & $0.5 \pm 0.01$ & $0.6 \pm 0.04$ & $0.4 \pm 0.1$ & $0.6 \pm 0.1$ & $0.7 \pm 0.02$ \\
\hline
\end{tabular}


Table A2. Protein, fat, and ash contents (g/100 g dry matter) of raw and extruded apple pomace (mean value \pm standard deviation, $n=3$ ).

\begin{tabular}{|c|c|c|c|c|c|}
\hline & Raw Material & $100-42-200$ & $100-22-200$ & $100-22-450$ & $100-22-700$ \\
\hline Protein content ${ }^{a}$ & $5.0 \pm 0.5^{\mathrm{B}}$ & $5.6 \pm 0.4^{\mathrm{B}, \mathrm{A}}$ & $5.5 \pm 0.4^{\mathrm{B}}$ & $5.3 \pm 0.2^{B}$ & $6.6 \pm 0.4^{\mathrm{A}}$ \\
\hline Fat content $\mathrm{a}^{\mathrm{a}}$ & $1.6 \pm 0.02 \mathrm{~A}$ & $1.6 \pm 0.1 \mathrm{~A}$ & $2.1 \pm 0.2 \mathrm{~A}, \mathrm{~B}$ & $2.3 \pm 0.4^{B}$ & $2.0 \pm 0.2^{\mathrm{A}, \mathrm{B}}$ \\
\hline Ash content ${ }^{a}$ & $1.4 \pm 0.2^{\mathrm{A}}$ & $1.1 \pm 0.1^{\mathrm{A}, \mathrm{B}}$ & $1.0 \pm 0.1^{\mathrm{A}, \mathrm{B}}$ & $1.0 \pm 0.1^{\mathrm{B}}$ & $1.0 \pm 0.2^{\mathrm{A}, \mathrm{B}}$ \\
\hline
\end{tabular}

${ }^{a}$ Mean values within a row that are marked with different letters differ significantly $(p<0.05)$.

Table A3. Contents of free mono- and disaccharides ( $\mathrm{g} / 100 \mathrm{~g}$ dry matter) of raw and extruded apple pomace (mean value \pm standard deviation, $n=3$ ).

\begin{tabular}{lccccc}
\hline & Raw Material & $\mathbf{1 0 0 - 4 2 - 2 0 0}$ & $\mathbf{1 0 0 - 2 2 - 2 0 0}$ & $\mathbf{1 0 0 - 2 2 - 4 5 0}$ & $\mathbf{1 0 0 - 2 2 - 7 0 0}$ \\
\hline Glucose $^{\mathrm{a}}$ & $2.8 \pm 0.3^{\mathrm{A}}$ & $3.5 \pm 0.3^{\mathrm{A}}$ & $2.9 \pm 0.1^{\mathrm{A}}$ & $3.1 \pm 0.1^{\mathrm{A}}$ & $3.0^{\mathrm{A}} \pm 0.5^{\mathrm{A}}$ \\
Fructose $^{\mathrm{a}}$ & $8.8 \pm 0.3^{\mathrm{A}}$ & $5.1 \pm 0.5^{\mathrm{B}}$ & $4.1 \pm 0.3^{\mathrm{C}, \mathrm{D}}$ & $4.3 \pm 0.1^{\mathrm{B}, \mathrm{C}}$ & $3.4^{\mathrm{D}} \pm 0.1^{\mathrm{D}}$ \\
Sucrose $^{\mathrm{a}}$ & $2.3 \pm 0.4^{\mathrm{B}, \mathrm{C}}$ & $4.4 \pm 0.2^{\mathrm{A}}$ & $2.8 \pm 0.2^{\mathrm{B}}$ & $1.9 \pm 0.2^{\mathrm{C}}$ & $0.7^{\mathrm{B}} \pm 0.5^{\mathrm{D}}$ \\
Maltose & $1.4 \pm 0.3$ & $\mathrm{~b}$ & $\mathrm{~b}$ & $\mathrm{~b}$ & $\mathrm{~b}$ \\
\hline
\end{tabular}

${ }^{\mathrm{a}}$ Mean values within a row that are marked with different letters differ significantly $(p<0.05) ;{ }^{b}$ Below the limit of quantification.

Table A4. Starch contents (g/100 g dry matter) of raw and extruded apple pomace (mean value \pm standard deviation, $n=3$ ).

\begin{tabular}{lccccc}
\hline & Raw Material & $\mathbf{1 0 0 - 4 2 - 2 0 0}$ & $\mathbf{1 0 0 - 2 2 - 2 0 0}$ & $\mathbf{1 0 0 - 2 2 - 4 5 0}$ & $\mathbf{1 0 0 - 2 2 - 7 0 0}$ \\
\hline Starch content $^{\mathrm{a}}$ & $11.6 \pm 0.7^{\mathrm{A}}$ & $9.2 \pm 0.8^{\mathrm{B}}$ & $8.8 \pm 0.6^{\mathrm{B}}$ & $8.3 \pm 0.6^{\mathrm{B}}$ & $8.5 \pm 0.8^{\mathrm{B}}$ \\
\hline
\end{tabular}

${ }^{a}$ Mean values within a row that are marked with different letters differ significantly $(p<0.05)$.

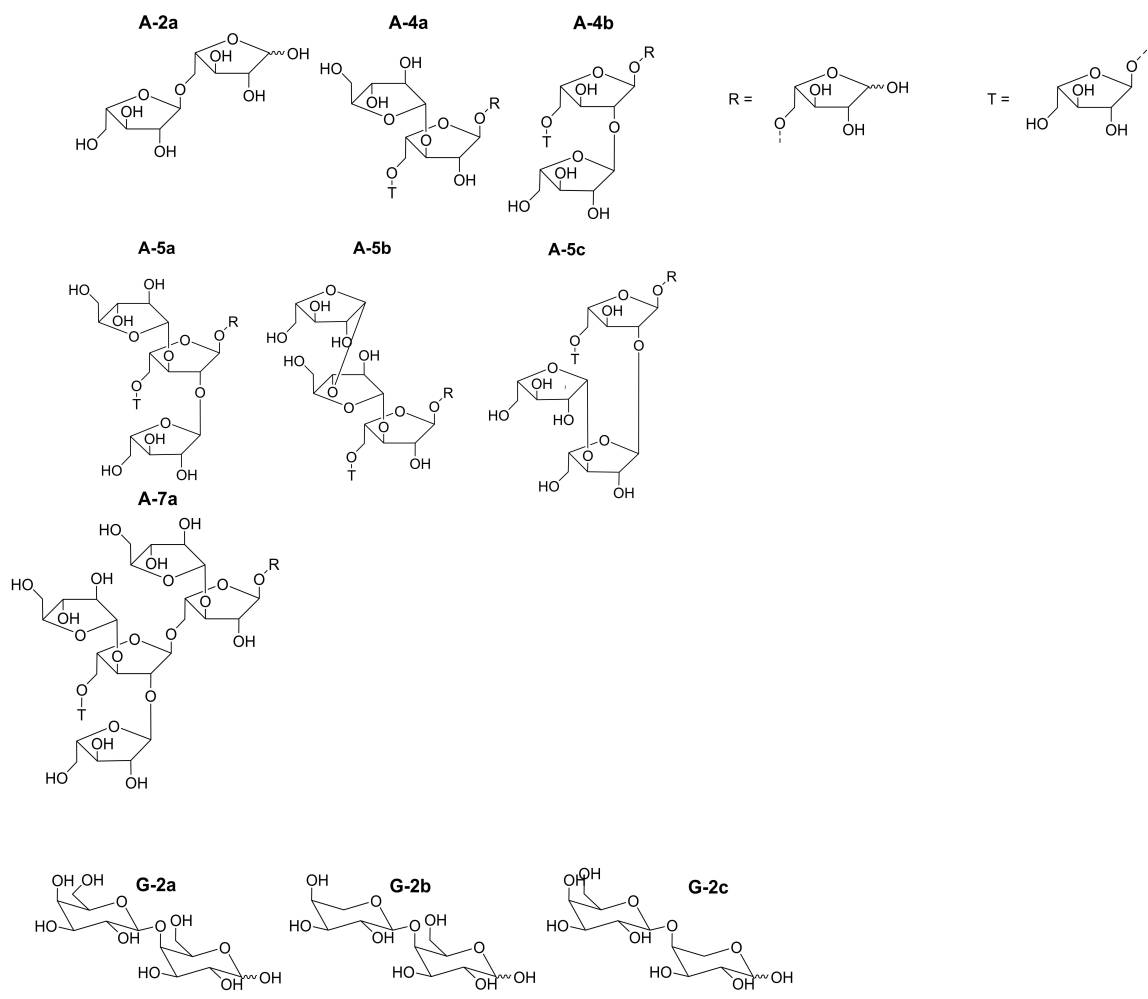

Figure A1. Structures of arabinan and galactan oligosaccharides of raw and extruded apple pomace dietary fiber after enzymatic cleavage by endo-arabinanase and endo-galactanase. R: reducing end, $\mathrm{T}$ : terminal end. 
Table A5. Glycosidic linkages (partially methylated alditol acetates; $\mathrm{mol} \%$ ) of soluble dietary fiber of raw and extruded apple pomace (mean value \pm range/2, $n=2$ ). t: terminal, $p$ : pyranose, $f$ : furanose, Rha: rhamnose, Ara: arabinose, Gal: galactose, Glc: glucose, Man: mannose, Xyl: xylose.

\begin{tabular}{|c|c|c|c|c|c|}
\hline & $\begin{array}{c}\text { Raw } \\
\text { Material }\end{array}$ & $100-40-200$ & $100-20-200$ & $100-20-450$ & $100-20-700$ \\
\hline 1,2-Rhap & a & $1.4 \pm 0.03$ & $1.4 \pm 0.03$ & $1.2 \pm 0.6$ & $1.0 \pm 0.5$ \\
\hline 1,2,4-Rhap & $0.9 \pm 0.02$ & $0.9 \pm 0.03$ & $0.9 \pm 0.03$ & $0.9 \pm 0.4$ & $1.2 \pm 0.01$ \\
\hline$\sum$ Rha & $0.9 \pm 0.02$ & $2.3 \pm 0.1$ & $2.3 \pm 0.1$ & $2.1 \pm 1.0$ & $2.2 \pm 0.5$ \\
\hline t-Araf & $33.3 \pm 1.2$ & $25.7 \pm 0.6$ & $25.4 \pm 0.6$ & $24.5 \pm 1.9$ & $20.8 \pm 0.1$ \\
\hline t-Arap & $\mathrm{a}$ & $0.8 \pm 0.01$ & $0.8 \pm 0.1$ & $0.9 \pm 0.3$ & $0.9 \pm 0.01$ \\
\hline 1,5-Araf $/ 1,4$-Ara $p$ & $21.1 \pm 0.4$ & $19.9 \pm 0.4$ & $19.7 \pm 0.4$ & $21.2 \pm 0.8$ & $18.3 \pm 0.5$ \\
\hline 1,3-Araf & $\mathrm{a}$ & $3.3 \pm 0.1$ & $3.3 \pm 0.1$ & $4.3 \pm 0.3$ & $2.4 \pm 0.9$ \\
\hline 1,2,5-Araf & $1.3 \pm 0.1$ & $2.2 \pm 0.1$ & $2.2 \pm 0.2$ & $2.3 \pm 0.5$ & $2.1 \pm 0.1$ \\
\hline 1,3,5-Araf & $8.2 \pm 0.5$ & $8.2 \pm 0.2$ & $8.1 \pm 0.2$ & $9.5 \pm 0.2$ & $7.9 \pm 0.4$ \\
\hline 1,2,3,5-Araf & $9.2 \pm 3.0$ & $11.8 \pm 0.2$ & $11.6 \pm 0.2$ & $12.8 \pm 0.9$ & $7.6 \pm 1.0$ \\
\hline$\sum$ Ara & $73,1 \pm 4.0$ & $71.9 \pm 1.4$ & $71.2 \pm 1.5$ & $75.5 \pm 4.9$ & $60.1 \pm 3.0$ \\
\hline $\mathrm{t}-\mathrm{Gal} p$ & $1.1 \pm 0.1$ & $2.5 \pm 0.04$ & $2.5 \pm 0.04$ & $2.1 \pm 0.3$ & $3.4 \pm 0.03$ \\
\hline 1,4-Galp & $2.3 \pm 0.3$ & $6.2 \pm 1.7$ & $6.1 \pm 1.7$ & $5.1 \pm 0.8$ & $7.7 \pm 1.3$ \\
\hline 1,6-Galp & a & a & $0.3 \pm 0.04$ & a & a \\
\hline$\sum \mathrm{Gal}$ & $3.3 \pm 0.5$ & $8.7 \pm 1.7$ & $8.9 \pm 1.8$ & $7.3 \pm 1.2$ & $11.0 \pm 1.4$ \\
\hline $\mathrm{t}-\mathrm{Gl} c p$ & $2.4 \pm 0.2$ & $0.8 \pm 0.01$ & $0.8 \pm 0.01$ & $0.8 \pm 0.2$ & $0.7 \pm 0.1$ \\
\hline 1,4-Glcp & $12.4 \pm 1.9$ & $7.8 \pm 0.2$ & $7.7 \pm 0.2$ & $5.4 \pm 1.2$ & $10.8 \pm 1.2$ \\
\hline 1,4,6-Glcp & $1.2 \pm 0.1$ & $2.7 \pm 0.01$ & $2.7 \pm 0.01$ & $2.8 \pm 0.01$ & $4.8 \pm 0.1$ \\
\hline$\sum$ Glc & $15.9 \pm 2.2$ & $11.3 \pm 0.2$ & $11.2 \pm 0.2$ & $9.0 \pm 1.4$ & $16.3 \pm 1.3$ \\
\hline 1,4-Man $p$ & $1.4 \pm 0.1$ & $1.0 \pm 0.1$ & $1.0 \pm 0.1$ & $0.8 \pm 0.2$ & $1.6 \pm 0.03$ \\
\hline$\sum$ Man & $1.4 \pm 0.1$ & $1.0 \pm 0.2$ & $1.0 \pm 0.1$ & $0.8 \pm 0.2$ & $1.6 \pm 0.03$ \\
\hline$\overline{\mathrm{t}}-\mathrm{Xyl} p$ & $3.5 \pm 0.2$ & $3.6 \pm 0.1$ & $3.5 \pm 0.1$ & $4.1 \pm 0.1$ & $5.7 \pm 0.4$ \\
\hline $1,2-\mathrm{Xyl} p \mathrm{~b}$ & $0.8 \pm 0.2$ & $0.7 \pm 0.02$ & $1.2 \pm 0.02$ & $0.5 \pm 0.03$ & $1.4 \pm 0.05$ \\
\hline $1,4-X y l p^{b}$ & $1.0 \pm 0.1$ & $0.5 \pm 0.03$ & $0.7 \pm 0.01$ & $0.7 \pm 0.003$ & $1.7 \pm 0.5$ \\
\hline$\sum \mathrm{Xyl}$ & $5.4 \pm 0.5$ & $4.8 \pm 0.1$ & $5.4 \pm 0.1$ & $5.3 \pm 0.1$ & $8.9 \pm 1.0$ \\
\hline
\end{tabular}

${ }^{a}$ Not detected; ${ }^{b}$ Coeluting, determined from the area ratio of the characteristic fragment ion peaks. 1,2-Xyl $p: m / z$ 117, 1,4-Xylp: $\mathrm{m} / \mathrm{z} 118$.

Table A6. Arabinan and galactan oligosaccharide composition (mol\%) after incubation of soluble dietary fiber of raw and extruded apple pomace with endo-arabinanase and endo-galactanase (mean value \pm range/2, $n=2$ ).

\begin{tabular}{cccccc}
\hline & Raw Material & $\mathbf{1 0 0 - 4 0 - 2 0 0}$ & $\mathbf{1 0 0 - 2 0 - 2 0 0}$ & $\mathbf{1 0 0 - 2 0 - 4 5 0}$ & $\mathbf{1 0 0 - 2 0 - 7 0 0}$ \\
\hline A-2a & $84.7 \pm 0.01$ & $79.0 \pm 1.4$ & $77.0 \pm 2.9$ & $78.1 \pm 2.4$ & $78.8 \pm 0.2$ \\
A-4a & $6.9 \pm 0.1$ & 0.01 & $14.0 \pm 2.5$ & $15.1 \pm 0.4$ & $14.7 \pm 0.2$ \\
A-4b & - & $3.1 \pm 0.03$ & $3.4 \pm 0.8$ & $3.6 \pm 0.1$ & $3.3 \pm 0.04$ \\
A-5a & $3.4 \pm 0.1$ & $4.9 \pm 1.4$ & $3.3 \pm 1.2$ & $3.1 \pm 1.7$ & $2.1 \pm 0.1$ \\
A-5b & $2.6 \pm 0.1$ & a & $2.3 \pm 0.9$ & a & $1.1 \pm 0.1$ \\
A-5c & $0.7 \pm 0.0004$ & a & a & a & - \\
A-7a & $1.7 \pm 0.1$ & - & - & - & - \\
\hline G-2a & 100.0 & Galactan oligosaccharide & & 100.0 \\
G-2b & - & 100.0 & $99.0 \pm 0.1$ & 100.0 & - \\
G-2c & - & a & & - & - \\
\hline
\end{tabular}

a Below the limit of quantification. 


\section{References}

1. Gorinstein, S.; Zachwieja, Z.; Fołta, M.; Barton, H.J.; Piotrowicz, J.; Zemser, M.; Weisz, M.; Trakhtenberg, S.; Martín-Belloso, O. Comparative contents of dietary fiber, total phenolics, and minerals in persimmons and apples. J. Agric. Food Chem. 2001, 49, 952-957. [CrossRef] [PubMed]

2. Nawirska, A.; Kwaśniewska, M. Dietary fibre fractions from fruit and vegetable processing waste. Food Chem. 2005, 91, 221-225. [CrossRef]

3. Diñeiro García, Y.; Valles, B.S.; Picinelli Lobo, A. Phenolic and antioxidant composition of by-products from the cider industry: Apple pomace. Food Chem. 2009, 117, 731-738. [CrossRef]

4. Schieber, A.; Hilt, P.; Streker, P.; Endreß, H.-U.; Rentschler, C.; Carle, R. A new process for the combined recovery of pectin and phenolic compounds from apple pomace. Innov. Food Sci. Emerg. Technol. 2003, 4, 99-107. [CrossRef]

5. Sharma, S.; Bansal, S.; Mangal, M.; Dixit, A.K.; Gupta, R.K.; Mangal, A. Utilization of Food Processing By-products as Dietary, Functional and Novel Fibre: A Review. Crit. Rev. Food Sci. Nutr. 2016, 56, 1647-1661. [CrossRef]

6. $\quad$ Elleuch, M.; Bedigian, D.; Roiseux, O.; Besbes, S.; Blecker, C.; Attia, H. Dietary fibre and fibre-rich by-products of food processing: Characterisation, technological functionality and commercial applications: A review. Food Chem. 2011, 124, 411-421. [CrossRef]

7. Figuerola, F.; Hurtado, M.L.; Estévez, A.M.; Chiffelle, I.; Asenjo, F. Fibre concentrates from apple pomace and citrus peel as potential fibre sources for food enrichment. Food Chem. 2005, 91, 395-401. [CrossRef]

8. O'Shea, N.; Arendt, E.K.; Gallagher, E. Dietary fibre and phytochemical characteristics of fruit and vegetable by-products and their recent applications as novel ingredients in food products. Innov. Food Sci. Emerg. Technol. 2012, 16, 1-10. [CrossRef]

9. Schieber, A.; Stintzing, F.C.; Carle, R. By-products of plant food processing as a source of functional compounds-recent developments. Trends Food Sci. Technol. 2001, 12, 401-413. [CrossRef]

10. Sloan, E. Dietary fiber moves back into mainstream. Food Technol. 2001, 55, 18.

11. Carson, K.; Collins, J.; Penfield, M. Unrefined, Dried Apple Pomace as a Potential Food Ingredient. J. Food Sci. 1994, 59, 1213-1215. [CrossRef]

12. Chen, H.; Rubenthaler, G.L.; Leung, H.K.; Baranowski, J.D. Chemical, Physical, and Baking Properties of Apple Fiber. Cereal Chem. 1988, 65, 244-247.

13. Fernández-López, J.; Fernández-Ginés, J.; Aleson-Carbonell, L.; Sendra, E.; Sayas-Barberá, E.; Pérez-Alvarez, J.A. Application of functional citrus by-products to meat products. Trends Food Sci. Technol. 2004, 15, 176-185. [CrossRef]

14. Henríquez, C.; Speisky, H.; Chiffelle, I.; Valenzuela, T.; Araya, M.; Simpson, R.; Almonacid, S. Development of an Ingredient Containing Apple Peel, as a Source of Polyphenols and Dietary Fiber. J. Food Sci. 2010, 75, H172-H181. [CrossRef] [PubMed]

15. Larrea, M.; Chang, Y.; Martínez-Bustos, F. Some functional properties of extruded orange pulp and its effect on the quality of cookies. LWT 2005, 38, 213-220. [CrossRef]

16. Masoodi, F.A.; Chauhan, G.S. Use of apple pomace as a source of dietary fiber in wheat bread. J. Food Process. Preserv. 1998, 22, 255-263. [CrossRef]

17. Sudha, M.L.; Vetrimani, R.; Leelavathi, K. Influence of fibre from different cereals on the rheological characteristics of wheat flour dough and on biscuit quality. Food Chem. 2007, 100, 1365-1370. [CrossRef]

18. Bengtsson, H.; Tornberg, E. Physicochemical characterization of fruit and vegetable fiber suspensions. I: Effect of homogenization. J. Texture Stud. 2011, 42, 268-280. [CrossRef]

19. Bengtsson, H.; Wikberg, J.; Tornberg, E. Physicochemical characterization of fruit and vegetable fiber suspensions. II: Effect of variations in heat treatment. J. Texture Stud. 2011, 42, 281-290. [CrossRef]

20. Bouvier, J.-M.; Campanella, O.H. Extrusion Processing Technology; Wiley: Hoboken, NJ, USA, 2014.

21. Huang, Y.-L.; Ma, Y.-S. The effect of extrusion processing on the physiochemical properties of extruded orange pomace. Food Chem. 2016, 192, 363-369. [CrossRef]

22. Redgwell, R.J.; Curti, D.; Robin, F.; Donato, L.; Pineau, N. Extrusion-Induced Changes to the Chemical Profile and Viscosity Generating Properties of Citrus Fiber. J. Agric. Food Chem. 2011, 59, 8272-8279. [CrossRef] [PubMed] 
23. Ralet, M.-C.; Thibualt, J.-F.; Della Valle, G. Solubilization of Sugar-beet Pulp Cell Wall Polysaccharides by Extrusion-cooking. LWT-Food Sci. Technol. 1991, 24, 107-112.

24. Ng, A.; Lecain, S.; Parker, M.L.; Smith, A.C.; Waldron, K.W. Modification of cell-wall polymers of onion waste III. Effect of extrusion-cooking on cell-wall material of outer fleshy tissues. Carbohydr. Polym. 1999, 39, 341-349. [CrossRef]

25. Wefers, D.; Flörchinger, R.; Bunzel, M. Detailed Structural Characterization of Arabinans and Galactans of 14 Apple Cultivars Before and After Cold Storage. Front. Plant. Sci. 2018, 9, 9. [CrossRef]

26. Laufenberg, G.; Kunz, B.; Nystroem, M. Transformation of vegetable waste into value added products. Bioresour. Technol. 2003, 87, 167-198. [CrossRef]

27. Shalini, R.; Gupta, D.K. Utilization of pomace from apple processing industries: A review. J. Food Sci. Technol. 2010, 47, 365-371. [CrossRef]

28. Karkle, E.L.; Alavi, S.; Dogan, H. Cellular architecture and its relationship with mechanical properties in expanded extrudates containing apple pomace. Food Res. Int. 2012, 46, 10-21. [CrossRef]

29. Leyva-Corral, J.; Quintero-Ramos, A.; Camacho-Dávila, A.; Zazueta-Morales, J.D.J.; Aguilar-Palazuelos, E.; Ruiz-Gutiérrez, M.G.; Meléndez-Pizarro, C.O.; De Jesus Ruiz-Anchondo, T. Polyphenolic compound stability and antioxidant capacity of apple pomace in an extruded cereal. LWT-Food Sci. Technol. 2016, 65, 228-236. [CrossRef]

30. O'Shea, N.; Arendt, E.; Gallagher, E. Enhancing an Extruded Puffed Snack by Optimising Die Head Temperature, Screw Speed and Apple Pomace Inclusion. Food Bioprocess. Technol. 2014, 7, 1767-1782. [CrossRef]

31. Singha, P.; Singh, S.K.; Muthukumarappan, K. Textural and structural characterization of extrudates from apple pomace, defatted soy flour and corn grits. J. Food Process. Eng. 2019, 42, e13046. [CrossRef]

32. Hwang, J.; Choi, J.; Kim, C.; Kim, C.-T. Solubilization of apple pomace by extrusion. J. Food Process. Preserv. 1998, 22, 477-491. [CrossRef]

33. Hwang, J.-K.; Kim, C.-J.; Kim, C.-T. Extrusion of Apple Pomace Facilitates Pectin Extraction. J. Food Sci. 1998, 63, 841-844. [CrossRef]

34. Liu, G.; Ying, D.Y.; Guo, B.; Cheng, L.J.; May, B.; Bird, T.; Sanguansri, L.; Cao, Y.; Augustin, M.A.; Bird, A. Extrusion of apple pomace increases antioxidant activity upon in vitro digestion. Food Funct. 2019, 10, 951-963. [CrossRef] [PubMed]

35. Koch, L.; Emin, M.A.; Karbstein, H. Influence of processing conditions on the formation of whey protein-citrus pectin conjugates in extrusion. J. Food Eng. 2017, 193, 1-9. [CrossRef]

36. Anderson, R.A. Water Absorption and Solubility and Amylograph Characteristics of Roll-Cooked Small Grain Products. Cereal Chem. J. 1982, 59, 265.

37. Caprez, A.; Arrigoni, E.; Amadò, R.; Neukom, H. Influence of different types of thermal treatment on the chemical composition and physical properties of wheat bran. J. Cereal Sci. 1986, 4, 233-239. [CrossRef]

38. Wefers, D.; Gmeiner, B.M.; Tyl, C.E.; Bunzel, M. Characterization of diferuloylated pectic polysaccharides from quinoa (Chenopodium quinoa WILLD.). Phytochemistry 2015, 116, 320-328. [CrossRef]

39. Prosky, L.; Asp, N.-G.; Furda, I.; Devries, J.W.; Schweizer, T.F.; Harland, B.F. Determination of Total Dietary Fiber in Foods and Food Products: Collaborative Study. J. Assoc. Off. Anal. Chem. 1985, 68, 677-679. [CrossRef]

40. McCleary, B.V.; De Vries, J.W.; I Rader, J.; Cohen, G.; Prosky, L.; Mugford, D.C.; Champ, M.; Okuma, K.; Abercrombie, L.; Ames, N.; et al. Determination of Total Dietary Fiber (CODEX Definition) by Enzymatic-Gravimetric Method and Liquid Chromatography: Collaborative Study. J. AOAC Int. 2010, 93, 221-233. [CrossRef]

41. Urbat, F.; Müller, P.; Hildebrand, A.; Wefers, D.; Bunzel, M. Comparison and Optimization of Different Protein Nitrogen Quantitation and Residual Protein Characterization Methods in Dietary Fiber Preparations. Front. Nutr. 2019, 6, 127. [CrossRef]

42. Bunzel, M.; Ralph, J.; Marita, J.M.; Hatfield, R.D.; Steinhart, H. Diferulates as structural components in soluble and insoluble cereal dietary fibre. J. Sci. Food Agric. 2001, 81, 653-660. [CrossRef]

43. Gniechwitz, D.; Reichardt, N.; Blaut, M.; Steinhart, H.; Bunzel, M. Dietary Fiber from Coffee Beverage: Degradation by Human Fecal Microbiota. J. Agric. Food Chem. 2007, 55, 6989-6996. [CrossRef] [PubMed]

44. Sweet, D.P.; Shapiro, R.H.; Albersheim, P. Quantitative analysis by various g.l.c. response-factor theories for partially methylated and partially ethylated alditol acetates. Carbohydr. Res. 1975, 40, 217-225. [CrossRef] 
45. Wefers, D.; Bunzel, M. Arabinan and Galactan Oligosaccharide Profiling by High-Performance Anion-Exchange Chromatography with Pulsed Amperometric Detection (HPAEC-PAD). J. Agric. Food Chem. 2016, 64, 4656-4664. [CrossRef] [PubMed]

46. Blumenkrantz, N.; Asboe-Hansen, G. New Method for Quantitative Determination of Uranic Acids. Anal. Biochem. 1973, 54, 484-489. [CrossRef]

47. Chandra, R.P.; Ewanick, S.; Hsieh, C.; Saddler, J.N. The characterization of pretreated lignocellulosic substrates prior to enzymatic hydrolysis, part 1: A modified Simons' staining technique. Biotechnol. Prog. 2008, 24, 1178-1185. [CrossRef]

48. Inglesby, M.; Zeronian, S. Direct dyes as molecular sensors to characterize cellulose substrates. Cellulose 2002, 9, 19-29. [CrossRef]

49. Wiman, M.; Dienes, D.; Hansen, M.A.; Van Der Meulen, T.; Zacchi, G.; Liden, A. Cellulose accessibility determines the rate of enzymatic hydrolysis of steam-pretreated spruce. Bioresour. Technol. 2012, 126, 208-215. [CrossRef]

50. Emin, M.; Karbstein, H. Analysis of the dispersive mixing efficiency in a twin-screw extrusion processing of starch based matrix. J. Food Eng. 2013, 115, 132-143. [CrossRef]

51. Chang, M.-C.; Morris, W.C. Effect of Heat Treatments on Chemical Analysis of Dietary Fiber. J. Food Sci. 1990, 55, 1647-1650. [CrossRef]

52. Ralet, M.-C.; Saulnier, L.; Thibault, J.-F. Raw and extruded fibre from pea hulls. Part II: Structural study of the water-soluble polysaccharides. Carbohydr. Polym. 1993, 20, 25-34. [CrossRef]

53. Ralet, M.-C.; Axelos, M.A.; Thibault, J.-F. Gelation properties of extruded lemon cell walls and their water-soluble pectins. Carbohydr. Res. 1994, 260, 271-282. [CrossRef]

54. Ralet, M.-C.; Della Valle, G.; Thibault, J.-F. Raw and extruded fibre from pea hulls. Part I: Composition and physico-chemical properties. Carbohydr. Polym. 1993, 20, 17-23. [CrossRef]

55. Kunzek, H.; Kabbert, R.; Gloyna, D. Aspects of material science in food processing: Changes in plant cell walls of fruits and vegetables. Zeitschrift für Lebensmitteluntersuchung und-Forschung A 1999, 208, 233-250. [CrossRef]

56. Willenbacher, N.; Georgieva, K. Rheology of Disperse Systems. In Product Design and Engineering: Formulation of Gels and Pastes, 1st ed.; Bröckel, U., Meier, W., Wagner, G., Eds.; Wiley-VCH Verlag GmbH \& Co. KGaA: Weinheim, Germany, 2013; pp. 7-50. ISBN 978-3-527-33220-5.

57. Raghavendra, S.; Swamy, S.R.; Rastogi, N.K.; Raghavarao, K.; Kumar, S.; Tharanathan, R. Grinding characteristics and hydration properties of coconut residue: A source of dietary fiber. J. Food Eng. 2006, 72, 281-286. [CrossRef]

58. Brands, C.M.J.; Van Boekel, M.A.J.S. Kinetic Modeling of Reactions in Heated Monosaccharide-Casein Systems. J. Agric. Food Chem. 2002, 50, 6725-6739. [CrossRef]

59. Sudha, M.L.; Baskaran, V.; Leelavathi, K. Apple pomace as a source of dietary fiber and polyphenols and its effect on the rheological characteristics and cake making. Food Chem. 2007, 104, 686-692. [CrossRef]

60. Peña, M.J.; Carpita, N.C. Loss of Highly Branched Arabinans and Debranching of Rhamnogalacturonan I Accompany Loss of Firm Texture and Cell Separation during Prolonged Storage of Apple1. Plant. Physiol. 2004, 135, 1305-1313. [CrossRef]

61. Schmid, V.; Steck, J.; Mayer-Miebach, E.; Behsnilian, D.; Briviba, K.; Bunzel, M.; Karbstein, H.P.; Emin, M.A. Impact of defined thermomechanical treatment on the structure and content of dietary fiber and the stability and bioaccessibility of polyphenols of chokeberry (Aronia melanocarpa) pomace. Food Res. Int. 2020, 134, 109232. [CrossRef]

62. Inglesby, M.; Zeronian, S.; Elder, T. Aggregation of Direct Dyes Investigated by Molecular Modeling. Text. Res. J. 2002, 72, 231-239. [CrossRef]

(C) 2020 by the authors. Licensee MDPI, Basel, Switzerland. This article is an open access article distributed under the terms and conditions of the Creative Commons Attribution (CC BY) license (http://creativecommons.org/licenses/by/4.0/). 